December 2001

\title{
Monetary Policy in a Changing World: Rising Role of Expectations and the Anticipation Effect*
}

The Federal Reserve (Fed) has maintained a general trend toward increased transparency and gradualism. This paper investigates the implications of these historical developments for the anticipation of monetary policy actions and adjustment of interest rates. In a theoretical framework, we establish the Fed's ability to manipulate overnight rates via an "anticipation" effect. The anticipation effect is defined as interest rate adjustments that take place prior to a policy announcement (or prior to when the complementary open market operations associated with that policy action take place) due to market's improved ability to predict future policy actions. Our empirical results document that most market rates adjust to anticipated policy actions prior to the actual announcement. Because the market responds to policy announcements instantly, the Trading Desk does not need to act immediately after the target change and can wait until the market incorporates the new information that comes with the policy announcement.

JEL Classification Codes: E0, E4, E5

Keywords: Transparency, Liquidity Effect, Announcement Effect, Anticipation Effect

Selva Demiralp

Board of Governors of the Federal Reserve System

Division of Monetary Affairs

Washington, DC 20551

E-mail: selva.demiralp@frb.gov

*I would like to thank Sherry Edwards, David Lindsey, Athanasios Orphanides, Bill English, Darrel Cohen and the seminar participants at the Board of Governors for valuable comments on an earlier draft. I am also grateful to Oscar Jordá for his invaluable insights. The views expressed are those of the author's and not necessarily those of the Board of Governors of the Federal Reserve System or other members of its staff. 


\section{Introduction}

The process through which monetary policy decisions are transmitted to financial markets has changed significantly in recent years. The well-established secrecy and closed-door decisions gradually led the way to greater transparency, providing clearer communication to financial markets and the public regarding the Fed's objectives. In February 1994, the Federal Open Market Committee (FOMC) began to issue a public statement whenever it increased or decreased its target for the federal funds rate. While FOMC decisions were made in terms of a funds rate target in earlier years, these decisions were communicated to the market in a less explicit way through the activities of the Trading Desk at the Federal Reserve Bank of New York. In particular, the Trading Desk would "signal" a policy change by buying and selling securities so that conditions in the federal funds market would be consistent with an average federal funds rate near this target. With the new policy, when the FOMC announces changes in the target, the market reacts immediately, sometimes even before any open market operations take place to alter the supply of reserve balances. Following the terminology introduced by Guthrie and Wright (2000), this phenomenon is now commonly referred as "open mouth operations" in the literature.

The anticipation effect highlights the rising role of expectations due to institutional developments in the FOMC policy making that gave way to enhanced transparency and gradualism in policy decisions. The argument is that by becoming less secretive and more predictable, the Federal Reserve has gained the ability to influence interest rates prior to the announcement of the actual policy decision, and before the reserve balances are altered (i.e. prior to the complementary open market operations associated with the policy decision take place). Note that the focus here is different than the so called "announcement effect" which concentrates on interest rate adjustments after a policy announcement or associated operation. Yet, the two effects are interdependent because larger interest rate adjustments prior to a policy action imply fewer adjustments afterwards. In other words, when market rates respond to anticipated policy actions prior to a policy change, they only respond to the unanticipated component following the announcement. In that respect, the establishment of the anticipation effect reduces the announcement effect of each policy action. 
The anticipation effect mechanism derives its power from the establishment of credibility in the implementation of monetary policy. As the public and the markets establish faith in the monetary system, the Fed gains a better control of interest rates, not only by adjusting reserve pressures now, but also by signaling what it will do in the future. This is especially critical when it is viewed against the historical developments in the economy, which drastically improved the role of expectations in the monetary transmission mechanism. Over the last decade, the process of credit creation has moved increasingly out of the banking sector, over which the Fed has considerable direct power, into the financial markets, which it has much less ability to influence, except through expectations (see Mayer (2001) for a historical development of the Federal Reserve System). In that respect, the Fed has restored its ability to control credit markets, first by communicating its policy targets immediately and unambiguously, and second by establishing reliability regarding its long-term commitments to those targets.

Recently, the usefulness the anticipation effect has been carried to a new level as an effective policy tool, once the policy rate hits the zero nominal bound. In fact, at a time with relatively low nominal interest rates among most industrialized economies, policy makers are concerned about exhausting their potentials to stimulate the economy through interest rate adjustments. Under these circumstances, the anticipation effect emerges as a unique tool that can stimulate the economy by manipulating the term structure. Once nominal interest rate reaches the zero bound, if the policy makers can convince the public that monetary policy will remain expansionary for a longer period of time, expected future nominal short-term interest rates go down. This reduces current longer-term nominal interest rates, and stimulates aggregate demand (see Meyer (2001a)).

The specific operational change we emphasize in this paper is described in Meulendyke (1998) as: "A move to announce FOMC policy decisions on the day they were made began as an experiment in 1994. The approach was formalized in 1995." (p. 55). However, there is also reason to believe that the announcement effect had played a role even before 1994. In a cover note to a memorandum to the FOMC --dated August 14, 1991, Donald Kohn refers to the FOMC members' concerns regarding the instability caused by interest rate fluctuations following each policy change. He points out the goal 
towards implementing more gradual interest rate adjustments (thereby reducing the announcement effect) in the following lines: "In their discussion, Committee members seem to have been motivated by two related objectives. One was to reduce the "announcement effect" of each change in policy. [...]"

The anticipation effect has significant implications in the way that the policy is conducted, in the way we test for the liquidity effect, and in our understanding of the term structure of interest rates. This paper investigates the theoretical foundations of the anticipation effect and documents empirical evidence of the anticipation effect as early as 1989, when the federal funds futures market was established.

Several recent papers provide important background material and consider the announcement effect a serious policy issue. Guthrie and Wright (2000) present a theoretical model that justifies, in the context of New Zealand's monetary policy, the manner in which the market reacts to policy announcements. In their model, the monetary authority poses a credible intention when it discloses an unanticipated change in the target, thus alleviating the need for open market operations. For the U.S., Thornton (2001) studies the effects of Federal Reserve announcements on Treasury rates but finds rather inconclusive evidence. Taylor (2001) develops a theoretical model to show how changes in the target for the federal funds rate can affect the effective funds rate by incorporating expectations in the reserves market. Finally, Kuttner (2001) investigates the manner in which market interest rates respond to Federal Reserve actions by distinguishing between anticipated and unanticipated actions using federal funds futures rates.

In this paper, we attempt to reconcile and expand the earlier literature on the liquidity effect and overcome some of the shortcomings apparent in the previous studies. First, we elaborate on the model proposed by Taylor (2001), and analyze the properties of the equilibrium in the reserves market prior to an announcement, on the day of an announcement, and following the announcement over a given maintenance period. We analyze the testable implications derived from this analysis using daily data on interest rates, open market operations, and daily operating balances for the U.S. market. In their empirical analysis, Guthrie and Wright (2000) treat each policy announcement as a surprise in itself. While this approach may be suitable for the way in which monetary 
policy is implemented in New Zealand, such an assumption is not realistic for the U.S. where the market widely anticipates future policy actions and acts accordingly. For that reason, we use a more complex methodology to separate policy announcements into the expected and surprise components -- an extension of the technique described by Kuttner (2001) based on federal funds futures contracts.

The remainder of the paper is organized as follows: Section 2 provides a brief historical background on the institutional changes in the direction of transparency in the past couple of decades. Section 3 discusses the theoretical framework that allows us to analyze the anticipation and the announcement effects, based on Taylor (2001). Section 4 describes the methodology that we use to assess market's expectations of policy changes. Section 5 presents the empirical analysis, which provides new empirical evidence in favor of the anticipation effect. Section 6 concludes.

\section{A Historical Outlook at the U.S. Market}

In this section, we briefly go over the historical developments that have contributed to improved predictability of policy changes in the U.S. market, and discuss the circumstances that gave rise to these factors. Readers who are familiar with the history of U.S. monetary policy can skip this section and continue with section 3 .

In the past, central banks around the world tended to operate with considerable secrecy. The need for and the appropriateness of such secrecy was nearly unquestioned. Nevertheless, the Federal Reserve and other central banks have moved away from this secrecy and towards transparency in recent years. February 1994 can be viewed as a major landmark in the path towards transparency when the FOMC adopted the practice of announcing changes in its policy stance and began to disclose immediately the expected federal funds rate. In subsequent FOMC meetings, when no policy action had been taken, no formal announcement followed. However, in the absence of a policy action, the media were informed that the meeting had ended and that there would be no further announcements. Though these steps elucidated the current stance of monetary policy, the Committee recognized that it could further enhance the transparency of its actions by providing indications of factors that might affect the future direction of policy. The idea was that by providing more information about the Committee's views, financial markets could better comprehend future stance of monetary policy. When the stance of policy 
changed, the statement disclosing the action was used to provide an indication of the factors likely to influence the Committee's future decisions. Such information, however, was not provided when the Committee decided not to change its policy since no announcement accompanied such decisions. In order to bridge this gap, the Committee decided at its December 1998 meeting to announce major shifts in its view about prospective developments even in cases when the current policy setting remained unchanged. This step toward additional disclosure was first implemented in May 1999.

Under the current procedures, which were announced in January 2000, the FOMC issues a statement to the public immediately after every meeting. The statement provides information regarding the policy stance adopted at the meeting and the Committee's view about prospective economic developments. With the new procedures, the Committee adopted new language to describe its views about the economic outlook. The language indicates the Committee's sense of the balance of risks in the outlook against the background of the Committee's long-run goals of price stability and sustainable economic growth. Specifically, it indicates whether the Committee believes that the risks are "balanced with respect to prospects for both goals," "weighted mainly toward conditions that may generate heightened inflation pressures," or "weighted mainly toward conditions that may generate economic weakness."

\section{Motivations for Transparency}

In a speech given at the National Economists Club and Society of Government Economists, Vice Chairman Roger Ferguson (2001) defines transparency as: “... being forthcoming about goals and short-term tactics and, therefore, being easily and clearly understood." According to the Vice Chairman, the main reason for the role of transparency is that, the monetary policy that is most appropriate for long-run stability and growth of an economy may not be politically popular in the short run. Transparency facilitates a broad understanding of what the central bank is doing and therefore gives the public the tools to hold the independent central bank accountable.

The second reason that transparency is important is because clarity and predictability of policy decisions enhance the effectiveness of monetary policy. If the monetary authority can be clearer about what it is doing now and can explain the risks that may influence future policy, then market participants can improve their expectations 
of future short rates. Moreover, less uncertainty about monetary policy may reduce the premium for uncertainty. Consequently, transparency brings the rates that matter the most for the macroeconomy into closer alignment with the intentions of monetary policymakers.

Meanwhile, even though transparency conveys expectations about the future course of policy and affects longer-term interest rates sooner, expectations can also constrain monetary policy. Forecasts can prove inaccurate simply because the economy changes unexpectedly. Governor Laurence Meyer (2001b) underlines the restrictions of transparency by noting that if policymakers convey expectations of a move at the next meeting, but the policy does not deliver that change, longer-term rates may reverse their earlier move. This highlights the delicacy in maintaining a balance between encouraging more effective policy by guiding private sector expectations while, at the same time, avoiding policy being unduly affected by the same private sector expectations.

\section{Gradual Nature of Target Adjustments}

In addition to transparency, another factor that enhanced the predictability of monetary policy in the past few decades is the gradualist approach in making target adjustments, which has been adapted as the customary type of policy over time. A recent study by Lange, Sack, and Whitesell (2001) highlights the autoregressive nature of target changes as a major factor that has improved the market's forecasting performance. The authors argue that gradualism might arise from several reasons such as an intentional strategy of the FOMC to phase in periods of tightening or easing more gradually, or it could be due to the nature of shocks hitting the economy, which may have become more serially correlated over time. The gradual nature of target changes is further formalized by Hamilton and Jordá (2000) in an empirical model (Autoregressive Conditional Hazard Model) to forecast target changes.

\section{Policy Expectations and the Anticipation Effect}

The previous section discussed the implications of transparency and gradualism in the formation of expectations in the U.S. market. It is clear that the rapid evolution of monetary policy made inevitable an updating of the textbook model of the reserves market and the liquidity effect channel, which describes the use of monetary aggregates as the only tool in controlling interest rates. 
In this section, we present a theoretical model of the reserves market which integrates policy expectations in a simple textbook model and investigates the anticipation and the announcement effects.

\section{A Daily Model of the Reserves Market}

\section{Demand for Reserves}

Depository institutions hold reserves primarily for two reasons: (i) to meet legal reserve requirements, which are calculated on average over a two-week period called the maintenance period, and (ii) to facilitate interbank payments without incurring overnight overdrafts of the reserve account. Over the last several years, required reserve balances have dropped significantly (from \$20 billion in 1990, to \$10 billion in 1996 and to $\$ 4$ billion today) due to reductions in reserve requirements (in 1990, and 1992), and the introduction of sweep accounts (see Anderson and Raasche, 2000). However, banks still need reserves to meet interbank payments and to meet the public's demand for currency. Total balance requirements (or required operational balances) are the sum of required reserve balances (i.e. total required reserves less vault cash) plus required clearing balances (which is the amount contracted by the depository institutions to cover interbank payments and to offset charges for Reserve Bank services).

In formulating the daily demand for reserves over the maintenance period, Furfine (2000) highlights the role of intertemporal substitution over the maintenance period where the expectation of the next day's federal funds rate affects the demand for Fed balances today. Hamilton (1996) notes that this effect does not have to be full arbitrage, (i.e. today's funds rate moves one-to-one with expectations of tomorrow's rate) due to frictions that exist in the funds market such as transactions costs and limits on borrowing. In addition to these factors, changes in carryover positions also affect the banking system's ability to substitute reserve holdings from one maintenance period to the next (see Clouse and Dow (2000), Bartolini, Bertola, and Prati (2000) for more elaborate discussions on reserve management and the funds market). ${ }^{1}$

In order to analyze how expectations of a target change influence reserve demand, we investigate the maintenance period in three stages: the period before a target change,

\footnotetext{
${ }^{1}$ Carryover provisions allow banks to apply some of the excess reserves maintained in the current maintenance period to meet reserve requirements in the subsequent period.
} 
the day of a target change, and the period after a target change. For the purposes of this paper, we restrict our attention to changes in the expected funds rate that arise from anticipated policy moves, and assume that all other daily factors which influence tomorrow's expected funds rate remain constant. While this is admittedly a restrictive assumption, it allows us to investigate the implications of an anticipated target change without influencing the qualitative nature of the discussion significantly, and without getting into a rather complicated discussion about the daily determinants of the funds rate.

Accordingly, for a target change that takes place on day $t$ of the maintenance period, the demand for reserves can be expressed as:

$$
\begin{aligned}
& R_{t-j}=\theta-\alpha f_{t-j}-\gamma\left[f_{t-j}-E_{t-j}\left(f_{t}\right)\right], 1 \leq j<t \\
& R_{t}=\theta-\alpha f_{t}-\gamma\left(f_{t}-\rho_{t}\right) \\
& R_{t+j}=\theta-\alpha f_{t+j}-\gamma\left[f_{t+j}-E_{t+j}\left(f_{t+j+1}\right)\right], \quad 1 \leq j<14-t
\end{aligned}
$$

where $\theta, \alpha, \gamma>0 . R_{t-j}, R_{t}$, and $R_{t+j}$ describe the demand for reserves prior to a target change, on the day of a target change, and after a target change respectively. $f_{t}$ is the effective funds rate and $\rho_{t}$ is the federal funds rate target. $E_{t}$ is the expectations operator with information available up to day $t$.

$\gamma$ measures the size of intertemporal substitution proportional to the gap between today's effective funds rate and tomorrow's expected rate. Consequently, if $\gamma=1$, then there is perfect intertemporal substitution in response to anticipations, if $\gamma=0$, there is no intertemporal substitution in response to anticipations, and when $0<\gamma<1$, there is partial intertemporal substitution in response to anticipations. Both Furfine (2000) and Taylor (2001) indicate that $\gamma$ is close to but less than 1, due to down-weighting of the next day's interest rate.

Based on these functional specifications for reserve demand, the change in demand from any period prior to an announcement to the day of the announcement can be computed as the difference between (1-2) and (1-1): 
$\Delta R=R_{t}-R_{t-j}=-(\alpha+\gamma) \underbrace{\left(f_{t}-f_{t-j}\right)}_{\Delta f}+\gamma[\underbrace{\left[\left(\rho_{t}-E_{t-j}\left(f_{t}\right)\right]\right.}_{\text {Unanticipded Change }}$

Here, the first term captures the movement along the downward sloping demand curve due to daily interest rate fluctuations, whereas the second term captures the shifts in the demand schedule due to unanticipated policy changes.

In a similar way, the change in demand from the day of the announcement to the period after the announcement can be computed as [(1-3)-(1-2)]:

$\Delta R=R_{t+1}-R_{t}=-(\alpha+\gamma)(\underbrace{\left.f_{t}-f_{t}\right)}_{\Delta f}+\gamma[\underbrace{f_{t+j}-E_{t+j}\left(f_{t+j+1}\right)}_{=0}]$

Notice that in the period following a target change, there are no arbitrage opportunities arising from expected target changes since $f_{t+j}=E_{t+j}\left(f_{t+j+1}\right)=\rho_{t+1}$. Consequently, the third term in (1-3) drops out, indicating that the demand curve shifts back to its level at the beginning of the maintenance period, once the target change is announced and all arbitrage opportunities are exploited.

Intuitively, if the market expects a target change (say a raise) to take place on day $t$ of the maintenance period, demand for reserves rises prior to the target change, and declines after the target change. This is simply because it is more profitable for banks to meet their reserve requirements when the opportunity cost of holding reserves (i.e. overnight rate) is cheaper. In the framework of equation (1-1), demand for reserves increases by $\gamma\left[f_{t-j}-E_{t-j}\left(f_{t}\right)\right]$ which prevails until day $t$. Depending on the degree to which the Trading Desk accommodates demand (which will be discussed in the next section), the supply of reserves increases proportionally to demand.

When the Fed announces the new target level on day $t$, the effective rate may not immediately increase to the new target due to the timing of open market operations. ${ }^{2}$ The gap between the effective rate and the new target rate creates additional arbitrage opportunities, which motivate banks to adjust the demand for reserves further by an amount that was unanticipated by the market. In particular, if the actual change in the target is larger than what was anticipated prior to the announcement, i.e. $\rho_{t}>E_{t-1}\left(f_{t}\right)$,

\footnotetext{
2 The announcement is made at 2.15 EST whereas open market operations are conducted early in the day. Therefore, the Desk can only enter the market on the following day to adjust reserve supply consistent with the new target.
} 
then the demand for reserves increases proportionally to that surprise on day $t$, as indicated in equation (1-2).

After the Fed raises its target, the demand for reserves declines in the remainder of the maintenance period such that total reserves held over the maintenance period meets reserve requirements and any demand for excess reserves. This implies that the total increase in reserve holdings, due to an anticipated rise in the target is cut back by exactly the same amount in the remaining days of the maintenance period, as indicated in equation $(1-3) .^{3}$

\section{Supply of Reserves}

The Trading Desk of the Federal Reserve Bank of New York adjusts reserve balances via open market operations. In doing so, the Desk follows the FOMC's directive and keeps the daily effective funds rate at an average around the target. Taylor (2001) models Trading Desk's operations as a reaction function that relies on the previous day's miss of the effective federal funds rate from the Desk's target rate, which guides open market operations in the morning of the current day. Taylor's argument is that effective implementation of monetary policy requires a credible commitment that the Desk does its best to achieve the FOMC's target rate and thereby stabilizes expectations for the funds rate. Orphanides (2001) agrees with Taylor's motivation but emphasizes a "forward looking approach" to Desk operations. Based on the annual report of open market operations prepared by the Markets Group at the Federal Reserve Bank of New York, Orphanides suggests that the Desk sets the reserve supply each morning so that the effective rate is expected to be close to the target rate. Following Orphanides' remarks, we adopt the following reaction function in describing the Desk's behavior:

$$
b_{t}=b_{t-1}+\beta\left[E_{t-1}\left(f_{t}\right)-\rho_{t-1}\right], \quad 1 \leq t \leq 14, \quad \beta>0
$$

where

$b_{t}$ is the supply of Fed balances on day $t$,

$f_{t}$ is the daily effective funds rate on day $t$,

\footnotetext{
${ }^{3}$ In this paper, we focus on the reserves market and the effects of policy expectations prior to and after a policy change that takes place on day $t$. If the anticipated policy action does not materialize, demand for reserves still shifts prior to the anticipated move, as specified in (1-1). However, because there is no announcement on day $t$, demand for reserves declines by (1-3) in the remainder of the maintenance period (i.e. $t \leq j \leq 14$ ).
} 
$\rho_{t}$ is the federal funds rate target on day $t$.

Because the Trading Desk maintains the funds rate at the target level, one can argue that the expected future funds rate in a given day is equal to the expected target rate plus any forecasted deviations from the target that may exist due to institutional rigidities and calendar effects (see Hamilton (1996)). Equation (2) recognizes that the Desk takes account of anticipated variations in daily demand and supply schedules in the reserves market and attempts to offset shocks that are expected to prevail that day.

According to equation (2), the Trading Desk makes the necessary reserve adjustments with a lag. This is because the Desk intervenes the market in the morning before most of the day's trading takes place and before the effective daily rate is even calculated. Taylor (2001) further notes that lagged reserve balances enter the reaction function with a coefficient value equal to one, indicating that it is the change in reserves but not the level of reserves that responds to the deviation between the actual rate and the target rate.

The strictness of interest rate smoothing that is adopted by the Trading Desk is captured by parameter $\beta$. Ceteris paribus, the Desk increases supply if the daily rate is above the target rate (and vice versa), proportional to the value of $\beta$, which goes up as the degree of interest rate smoothing increases. In that respect, the parameter $\beta$ reflects the particular approach adopted by the manager, as a function of market conditions and policy expectations.

The time-varying nature of the parameter $\beta$ can be illustrated with the following example: Suppose that the market anticipates a rise in the target to take place later in the maintenance period. As a result, the Trading Desk predicts the demand for reserves to increase prior to the target change and decline afterwards. If the Desk adopts perfect interest rate smoothing (i.e. $\beta$ approaches its theoretical upper bound), it fully offsets demand pressures in order to maintain the existing target. Hence, reserves increase by an amount that is equal to the rise in demand prior to the announcement, and decline after the announcement, as the reserve need sharply declines (since most banks have already met their requirements with cheaper reserves). While perfect interest rate smoothing is a theoretically plausible scenario, Orphanides (2001) notes that strictness in interest rate 
smoothing may generate a fair amount of volatility in the volume of reserves in the days surrounding a target change. When the Desk is particularly concerned about generating this type volatility in the reserves market, the motivation to smooth interest rates may weaken, which reduces the value of $\beta$.

\section{Market Equilibrium}

After having established the functional relationships in which expectations enter the reserves market, our next step is to solve for the equilibrium interest rates and investigate the sensitivity of interest rates to the various parameters in the model by comparative statics analysis. However, before we go into the algebra, it is helpful to discuss the properties of the equilibrium in a graphical framework.

Figure 1 provides a graphical illustration of the reserves market. Without loss of generality, we exclude borrowed reserves from our analysis, which is consistent with increased avoidance of discount window borrowing in recent years (see Clouse (1994)). This simplification leaves us with a vertical supply curve that corresponds to nonborrowed reserves inelastically supplied by the Trading Desk.

In order to illustrate the way policy expectations affect the traditional liquidity effect channel, we consider three scenarios. The first scenario (shown in the first column in Table 1) describes the textbook liquidity effect channel. The second and the third scenarios depict the role of expectations in the reserves market. ${ }^{4}$ The second scenario illustrates the case where the Desk is primarily concerned with maintaining the existing target level and smooths out any deviations from the target by accommodating the demand for reserves. In contrast, the third scenario considers the opposite case where the Desk does not offset deviations from the existing target and allows market rates to be determined by anticipated target changes (i.e. $\beta=0$ ).

Suppose that at the beginning of the maintenance period, the reserves market is in equilibrium at $E_{0}$, with the funds rate target at $\rho_{t}$. Suppose further that the Fed aims to raise the target to a level such as $\rho_{t+1}$. Under the traditional liquidity effect theory, in order to achieve this interest rate adjustment, the Desk decreases reserve supply by $|\mathrm{AB}|$

\footnotetext{
${ }^{4}$ Without loss of generality, we set the partial elasticity with respect to tomorrow's interest rate equal to one (i.e. $\gamma=1$ ) as we describe these scenarios.
} 
(from $|\mathrm{OB}|$ to $|\mathrm{OA}|$ ). This is illustrated by a shift in the supply curve from $S_{0}$ to $S_{1}$, which moves the equilibrium point from $E_{0}$ to $E_{1}$, along the demand curve $D_{0}$.

The next two scenarios investigate how the inclusion of expectations changes this picture. Imagine that at the beginning of the maintenance period the market forms its expectations and anticipates a rise in the target to take place on day $t$ of the maintenance period. Suppose further that the expected new target is equal to: $E_{t-1}\left(f_{t}\right)=f^{e}$. Based on our earlier discussion, the demand curve shifts by $-\gamma\left[f_{t-1}-E_{t-1}\left(f_{t}\right)\right]$ (from $D_{0}$ to $D_{1}$ ), which remains at that level until day $t$. Recall from equation (2) that the Desk takes account of anticipated variations in demand and attempts to offset shocks that are expected to prevail in the reserves market. If the Fed aims to maintain interest rates at the current target, the Desk's response to this increase in demand is to ease reserve pressures by increasing the supply of reserves from $S_{0}$ to $S_{1}$ (which moves the equilibrium from $E_{0}$ to $\left.E_{2}\right) .^{5}$ In contrast, if the Desk allows market interest rates to move with expectations, the supply of reserves remains at $S_{0}$ and the equilibrium interest rate rises to the expected target level (at $E_{4}$ ) prior to a policy move.

Under either scenario II or III, the Fed does not have any incentive to counteract demand on the day of the announcement, which brings the supply schedule to a level that corresponds to the beginning of the period level at $S_{0}$. Meanwhile, following the announcement, the demand curve shifts up proportionally to the surprise component (from $D_{1}$ to $D_{2}$ ), which moves the equilibrium to $E_{3}$.

After the announcement, demand shifts back to $D_{0}$, where the size of the leftwards shift is equal to the size of the rightwards shift that took place due to the anticipated target change. The equilibrium settles at the new target level $E_{1}$, where the Desk decreases reserves consistent with the new target.

\footnotetext{
${ }^{5}$ Note that the "implied" equilibrium $\left(E_{4}\right)$ due to a demand shift occurs at $f^{e}$ as we set $\gamma=1$ in this example. In general, the implied equilibrium point will be less than (but close to) $f^{e}$ for values of $\gamma$ that are less than one. This is due to the limited adjustment rationale discussed in Taylor (2001) or Furfine (2000). If the Desk forecasts the change in demand accurately and acts pre-emptively, the shift in supply (from $S_{0}$ to $S_{2}$ ) occurs simultaneously as the demand shifts from $D_{0}$ to $D_{1}$. Thus, the market equilibrium shifts from $E_{0}$ to $E_{2}$, without ever reaching the implied level at $E_{4}$.
} 


\section{The Anticipation Effect and Open Market Operations}

The anticipation effect and the announcement effect can be described by reviewing the interaction between interest rates and nonborrowed reserves prior to and after a target change. These changes are summarized in the last three rows of Table 1. Under the traditional liquidity effect channel, expectations about target changes do not enter the interest rate determination mechanism and most of the adjustment takes place only after the target change. This corresponds to a tightening in reserves by $|\mathrm{AB}|$.

The anticipation effect builds upon market expectations prior to a target change. The anticipated target raise leads to an increase in demand, which puts upward pressure on interest rates prior to the change. Depending on the degree to which the Trading Desk offsets anticipated demand, the equilibrium interest rate approaches the new target rate before the actual announcement occurs. If there is perfect interest rate smoothing, nonborrowed reserves increases by $|\mathrm{BC}|$ prior to the target change and interest rates remain at the old target $\left(\rho_{t}\right)$ until the day of announcement. If there is no interest rate smoothing, then interest rates approach the anticipated new target level $\left(f^{e}\right)$ prior to the announcement. $^{6}$

On the day of the announcement, demand increases further, setting the effective rate equal to the new target level $E_{3}$, where a higher interest rate is achieved $\left(\rho_{t+1}>f^{e}>\rho_{t}\right)$ with no further tightening $\left(R_{t}=R_{t-1}=|O B|\right)$. In this framework, the anticipation effect has its full impact if the Fed does not accommodate demand changes and allows interest rates to adjust with expectations. This is the third scenario where the entire change in interest rates is achieved by a change in demand. Naturally, the third scenario cannot be feasible in a "repeated game" manner once the banking system incorporates the Desk's behavior in formulating their expectations. In other words, the demand for reserves would not increase prior to an anticipated target raise if the banking system realizes that the Trading Desk does not provide more funds at the cheaper rate prior to the forthcoming policy tightening. Nevertheless the alternative scenarios described in this section are still helpful in highlighting the following stylized facts:

\footnotetext{
${ }^{6}$ Note that as $\gamma$ approaches one, $f_{t}$ approaches $f^{e}$.
} 
i) The volume of open market operations that are needed to maintain an existing target prior to a target change goes up with the anticipation effect channel (relative to the traditional liquidity effect channel), if the Desk chooses to counteract anticipated demand.

ii) The volume of open market operations that are needed to enforce a target change following the announcement are identical (-|AC|) under both the liquidity effect channel and the announcement effect channels.

iii) Ceteris paribus, the anticipation effect (i.e. interest rate adjustments prior to the actual announcement) is stronger if the Desk does not counteract demand changes and allows the market rates to adjust with expectations (scenario three).

iv) Ceteris paribus, an improvement in the accuracy of forecasts implies that the shift in demand on the day of the announcement (due to a policy surprise) is smaller (i.e. $f^{e}$ approaches $\rho_{t+1}$ with an improvement in expectations), so long as there is not perfect interest rate smoothing. In other words, interest rate adjustments after the announcement get smaller with improvements in policy forecasts.

\section{Formation of Expectations}

In order to construct the functional specification for the expected funds rate (and hence to solve for the equilibrium interest rate), consider a simple graph of the reserves market such as the one illustrated in Figure 2. Assume that the equilibrium point $E_{0}$ is constructed prior to the first day of the maintenance period. That is, on day 0 the market is in equilibrium at point $E_{0}$, which is defined by the demand curve $D_{0}$ and the supply curve $S_{0}$. Following equations (1) and (2), this initial equilibrium point corresponds to a level of nonborrowed reserves given by $b_{0}$ and the effective funds rate given by $f_{0}$. The slope of the demand curve is equal to $\frac{1}{\alpha+\gamma}$, consistent with equation (1). Now, let's assume that as of time $i=0$, the market anticipates a target raise to take place on day $t$, such that $E_{0}\left(f_{t}\right)=f^{e}$, where the size of the anticipated target change is exogenously 
determined as: $(\text { anti } \Delta)_{i=0} \cdot{ }^{7}$ According to equation (1-1) this leads to a rightwards shift in the demand schedule by $\gamma$ (anti $\Delta$ ) consistent with the speculative demand for reserves. Depending on the accuracy of the Fed's forecast of this demand shift from $D_{0}$ to $D_{1}$, the Desk accommodates reserve supply on day 1, which increases nonborrowed reserves from $b_{0}$ to $b_{1}$. Equilibrium occurs at point $E_{1}$, which is determined at the intersection of $D_{1}$ and $S_{1}$, where the equilibrium funds rate occurs at $f_{1}{ }^{8}$

The above scenario can be used as a basis for the construction of expectations in a straightforward manner. In particular, we can express the slope of the demand curve as:

$$
\begin{aligned}
\text { Slope } & =\frac{1}{\alpha+\gamma}=\frac{\left|A E_{1}\right|}{|A B|}=\frac{\left|A E_{1}\right|}{\left|E_{0} B\right|-\left|E_{0} A\right|} \\
& \Rightarrow \frac{1}{\alpha+\gamma}=\frac{f_{1}-f_{0}}{\gamma(\text { anti } \Delta)-\left(b_{1}-b_{0}\right)} \\
& \Rightarrow f_{1}-f_{0}=\frac{1}{\alpha+\gamma}\left[\gamma(\text { anti } \Delta)-\left(b_{1}-b_{0}\right)\right] \\
& \Rightarrow f_{1}=f_{0}+\frac{1}{\alpha+\gamma}\left[\gamma(\text { anti } \Delta)-\left(b_{1}-b_{0}\right)\right]
\end{aligned}
$$

In a rational expectations framework, the expected funds rate is equal to the mathematical expectation of (3)',

$$
\left.E_{0}\left(f_{1}\right)=f_{0}+\frac{\gamma}{\alpha+\gamma}(\operatorname{anti} \Delta)-\frac{1}{\alpha+\gamma}\left[E_{0}\left(b_{1}\right)-b_{0}\right)\right]
$$

Furthermore, from (2),

$b_{1}=b_{0}+\beta\left[E_{0}\left(f_{1}\right)-\rho_{0}\right]$

\footnotetext{
${ }^{7}$ The time subscript in $(\text { anti } \Delta)_{i=0}$ refers to the day on which expectations of the new target are formed. In this example, expectations are formed prior to the first day of the maintenance period (i.e. day 0). Consequently, we can express this term as the difference between the forecasted target and the existing target on day 0: $(\text { anti } \Delta)_{i=0}=f^{e}-\rho_{0}$. We drop the time subscript later in the text, in order to provide notational simplicity. Unless it is indicated otherwise, expectations are assumed to be formed prior to the first day of the maintenance period.

${ }^{8}$ Figure 2 will be revisited later in the text, when anticipated and unanticipated target changes are discussed in more detail. We will leave this discussion for section 3.2, in order to keep our focus on the formation of expectations in this section.
} 
$\Rightarrow E_{0}\left(b_{1}\right)=b_{0}+\beta\left[E_{0}\left(f_{1}\right)-\rho_{0}\right]$ (By the law of iterative expectations)

Therefore,

$E_{0}\left(b_{1}\right)-b_{0}=\beta\left[E_{0}\left(f_{1}\right)-\rho_{0}\right]$

Substituting (4) into (3) provides the reduced form solution for the expected funds rate:

$E_{0}\left(f_{1}\right)=\left(\frac{\alpha+\gamma}{\alpha+\beta+\gamma}\right) f_{0}+\left(\frac{\gamma}{\alpha+\beta+\gamma}\right)($ anti $\Delta)+\left(\frac{\beta}{\alpha+\beta+\gamma}\right) \rho_{0}$

Or more generally,

$$
E_{i-1}\left(f_{i}\right)=\left(\frac{\alpha+\gamma}{\alpha+\beta+\gamma}\right) f_{i-1}+\left(\frac{\gamma}{\alpha+\beta+\gamma}\right)(\text { anti } \Delta)_{i-1}+\left(\frac{\beta}{\alpha+\beta+\gamma}\right) \rho_{i-1}, \forall i<t
$$

\subsection{Equilibrium Interest Rate prior to a Target Change}

Equilibrium interest rate prior to a target change can be derived by setting $(1-1)=$

(2) and substituting (5) for the expected funds rate. The resulting expression for the funds rate is given by (6):

$$
\begin{aligned}
& f_{i}=\Phi\left[\left(\theta-b_{i-1}\right)-\left(\frac{(\gamma+\alpha) \beta}{\alpha+\beta+\gamma}\right) f_{i-1}+\left(\frac{(\gamma-\beta) \gamma}{\alpha+\beta+\gamma}\right)(\text { anti })_{i-1}+\left(\frac{\gamma^{2}}{\alpha+\beta+\gamma}\right){\text { (revision })_{i}}+\left(\frac{(2 \gamma+\alpha) \beta}{\alpha+\beta+\gamma}\right) \rho_{i}\right] \\
& \forall i<t, \text { where } \Phi=\left(\frac{\alpha+\beta+\gamma}{(\alpha+\beta)(\alpha+\gamma)}\right)
\end{aligned}
$$

Note that we define "(revision $)_{i}$ " as the adjustment in the size of the expected target change on day $i$. In particular, $(\text { anti } \Delta)_{i}=(\text { anti } \Delta)_{i-1}+(\text { revision })_{i}$

\section{Comparative Statics based on Equation (6)}

In this section, we derive comparative statics based on equation (6) and investigate the properties of market equilibrium prior to a policy move. Testable implications derived from this exercise provide the base material for the empirical analysis in section 5. In particular, first derivatives (i.e. 1,2, and 3) present direct testable implications of the anticipation effect while the second derivatives (i.e. 1.1. through 3.3) present alternative theoretical circumstances under which the anticipation effect is expected to be stronger (or weaker). 


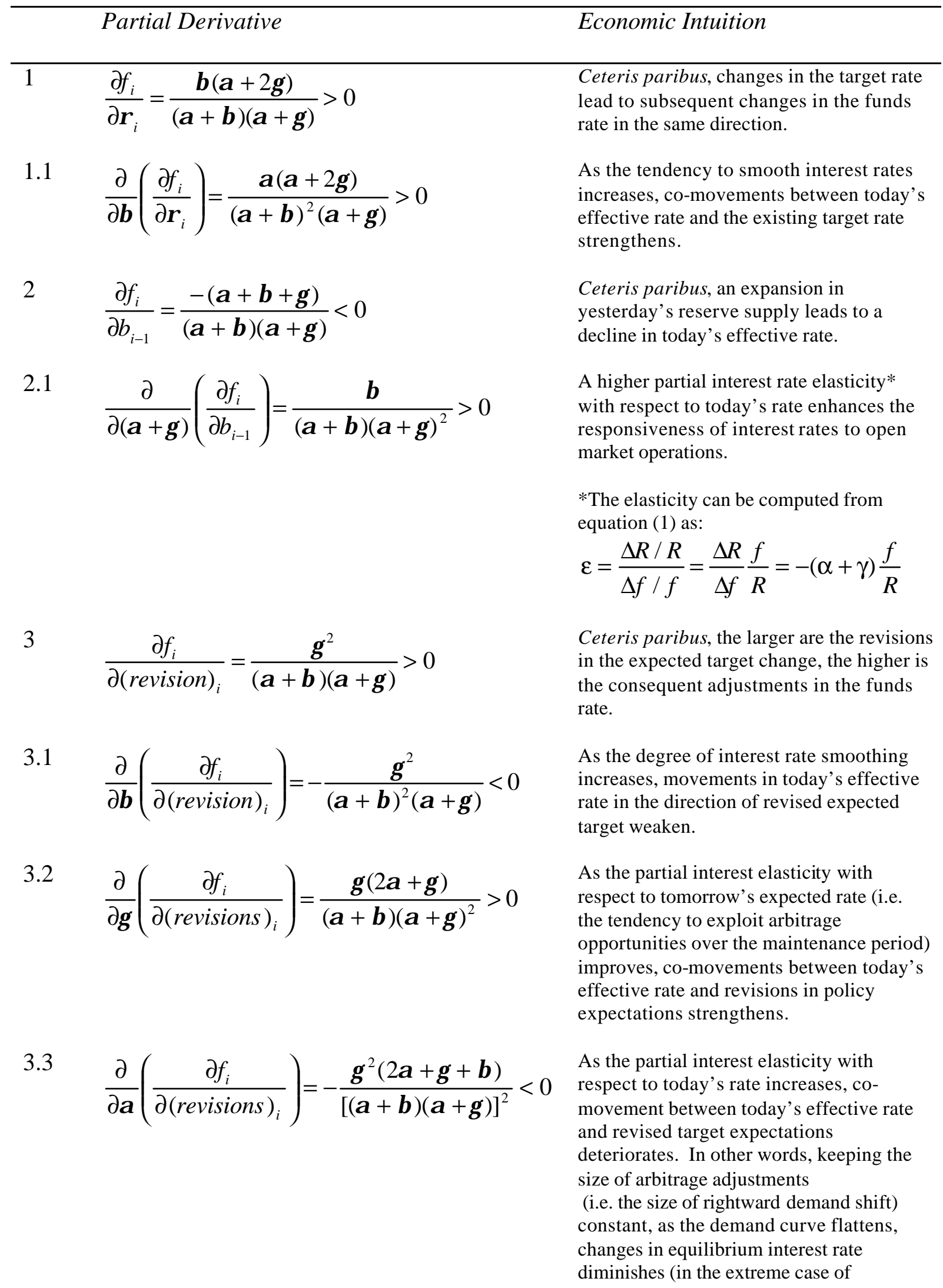

(continued) 
horizontal demand, an increase in the expected target rate leads to a rightwards shift in the demand curve, which moves each point proportionally to the right, leaving the equilibrium interest rate intact).

\subsection{Equilibrium Interest Rate on the Day of Target Change}

Equilibrium interest rate on the day of a target change is derived in a similar manner by setting (1-2)=(2) and substituting (5) for the expected funds rate.

Going back to Figure 2, the term $\left(f_{t}-\rho_{t}\right)$ in equation (1-2) can be expressed in an equivalent matter as:

$$
\rho_{t}-f_{t}=\underbrace{\rho_{t}-f^{e}}_{\text {Unanticipded } \Delta}+\underbrace{f^{e}-f^{a}}_{\text {PartialAdjustment }}+\underbrace{f^{a}-f_{t}}_{\text {IntersstRatesmooting }}
$$

where $f^{a}$ refers to the equilibrium interest rate that would occur if the Desk did not counteract anticipated demand.

Equation (7) points out that on the day of the target change, the gap between the effective funds rate and the new target rate can stem from three reasons: (i) forecast errors regarding the size of the target change, i.e. the "unanticipated component", (ii) the market's relative potential to exploit arbitrage opportunities (the size of this term increases with transaction costs and high penalties associated with overnight overdrafts) and (iii) the gap arising from the Desk's efforts to maintain the effective rate at the existing target level, i.e. "interest rate smoothing." Note that the third term drops under the extreme case of no interest rate smoothing.

As we substitute (7) in (1-2) and set (1-2)=(2), we get the following expression for the funds rate on the day of a target change:

$$
\begin{aligned}
f_{t}= & \frac{1}{\alpha}\left[\left(\theta-b_{t-1}\right)-\left(\frac{(\gamma+\alpha) \beta}{\alpha+\beta+\gamma}\right) f_{t-1}-\left(\frac{\beta \gamma}{\alpha+\beta+\gamma}\right)\left(\text { anti }_{t-1}\right)+\left(\frac{(\alpha+\gamma) \beta}{\alpha+\beta+\gamma}\right) \rho_{t-1}\right. \\
& +\gamma(\text { Unanticipaed } \Delta)+\gamma(\text { Partial Adjustment })+\gamma(\text { Interest Rate Smoothing })
\end{aligned}
$$

Next, we investigate the analytical properties of the equilibrium funds rate via comparative static analysis. 
Comparative Statics based on Equation (8)

\begin{tabular}{|c|c|c|}
\hline & Partial Derivative & Economic Intuition \\
\hline 4 & $\frac{\partial f_{t}}{\partial(\text { Unanticipated } \Delta)_{t}}=\frac{\gamma}{\alpha}>0$ & $\begin{array}{l}\text { Ceteris paribus, the larger is the } \\
\text { unanticipated target change, the larger are the } \\
\text { adjustments in the effective funds rate on the } \\
\text { day of target change. }\end{array}$ \\
\hline 4.1 & $\frac{\partial}{\partial \gamma}\left(\frac{\partial f_{t}}{\partial(\text { Unanticipated } \Delta)_{t}}\right)=\frac{1}{\alpha}>0$ & $\begin{array}{l}\text { As the partial interest elasticity with respect } \\
\text { to tomorrow's rate improves, co-movement } \\
\text { between the effective rate and unanticipated } \\
\text { target changes strengthens since the market } \\
\text { acts more aggressively to exploit arbitrage } \\
\text { opportunities. }\end{array}$ \\
\hline 4.2 & $\frac{\partial}{\partial \alpha}\left(\frac{\partial f_{t}}{\partial(\text { Unanticipated } \Delta)_{t}}\right)=-\frac{\gamma}{\alpha^{2}}<0$ & $\begin{array}{l}\text { As the partial interest elasticity with respect } \\
\text { to today's rate increases, co-movement } \\
\text { between today's effective rate and } \\
\text { unanticipated target changes goes down. }\end{array}$ \\
\hline 5 & $\frac{\partial f_{t}}{\partial(\text { Interest Smooting })}=\frac{\gamma}{\alpha}>0$ & $\begin{array}{l}\text { Ceteris paribus, the larger is the gap between } \\
\text { the anticipated target rate and the effective } \\
\text { funds rate prior to a change, the larger is the } \\
\text { interest rate adjustment on the day of } \\
\text { announcement. }\end{array}$ \\
\hline 6 & $\frac{\partial f_{t}}{\partial(\text { anti } \Delta)_{t-1}}=-\frac{\beta \gamma}{\alpha+\beta+\gamma}<0$ & $\begin{array}{l}\text { Ceteris paribus, the larger is the anticipated } \\
\text { target change prior to the announcement, the } \\
\text { smaller is the adjustment in the effective } \\
\text { funds rate on the day of target change. }\end{array}$ \\
\hline 6.1 & $\frac{\partial}{\partial \beta}\left(\frac{\partial f_{t}}{\partial(\text { anti } \Delta)_{t-1}}\right)=-\frac{\gamma(\alpha+\gamma)}{(\alpha+\beta+\gamma)^{2}}<0$ & $\begin{array}{l}\text { As interest rate smoothing increases, the } \\
\text { negative relationship between the anticipated } \\
\text { target changes prior to an announcement and } \\
\text { adjustments in the effective rate on the day of } \\
\text { announcement weakens. This is because less } \\
\text { interest rate adjustments take place in } \\
\text { response to anticipations under stricter } \\
\text { smoothing regimes. }\end{array}$ \\
\hline
\end{tabular}

\subsection{Equilibrium Level of Reserves}

The equilibrium level of reserves prior to a target change can be derived by first substituting (6) into (5) to obtain the expected equilibrium interest rate: $E_{i-1}\left(f_{i}^{E}\right)$. This step provides us with an expression that is a function of lagged reserves, the lagged funds rate, the anticipated target change, and the existing target rate. We then substitute 
$E_{i-1}\left(f_{i}^{E}\right)$ into (2) to obtain the equilibrium level of reserves prior to a target change. ${ }^{9}$ The equilibrium level of reserves on the day of a target change (and after the target change) are obtained in a similar manner. At this point, it is essential to recall the time-varying nature of parameter $\beta$, which goes down on the day of announcement as the motivation to counteract anticipated demand diminishes. In the limit $\beta$ approaches zero, as $b_{t}^{E}$ approaches $b_{i-1}$.

\section{Constructing Market Expectations: A Methodology based on Federal Funds Futures Contracts (Kuttner (2001))}

In order to carry out an empirical investigation of the anticipation effect, we need a measure of expectations of Fed policy actions. Kuttner (2001) describes a convenient way to compute an estimate of the policy surprise based on the price of federal funds futures contracts. Here, the key idea is that the spot rate for federal funds futures contract on a particular day $t$ reflects the expected average funds rate for that month, conditional on the information prevailing up to that date. ${ }^{10}$ Based on this fact, and knowing that the effective funds rate as a monthly average is very close to target rate (typically within a few basis points), the spot-month futures rate on any day $k$ prior to a target change can be expressed as:

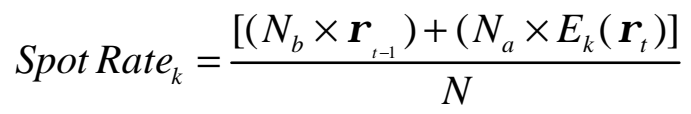

where $N_{b}$ is the number of days before a target change, $N_{a}$ is the number of days after a target change, and $N=N_{b}+N_{a}$ is the total number of days in a given month.

Assuming that the target change occurs on day $\tau$, the spot rate on the day of target change is given by:

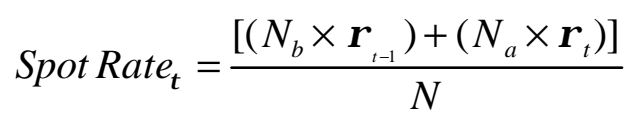

\footnotetext{
${ }^{9}$ Algebraic expressions for the equilibrium level of reserves and the expected funds rate are available from the author upon request.

${ }^{10}$ Naturally, this measure presumes that market participants are aware of the target change. If the market participants were unaware that the target has changed, expectations would not necessarily reflect the changes in the policy instrument. Empirical evidence suggests that the market was aware of interest rate targeting policies as early as 1989 , which is the starting year of our sample period (see e.g. Demiralp and Jorda (2001), Poole, Rasche and Thornton (2001)).
} 
Consequently, as we compute the difference between the spot rates prior to and after the target change i.e. (12)-(11), we get the policy surprise as of day $k:^{11}$

$$
\text { Spot Rate }_{\tau}-\text { Spot Rate }_{k}=\Phi \underbrace{\left[\rho_{t}-E_{k}\left(\rho_{t}\right)\right]}_{\text {Unanticipdedtargetchangeas of day } k}
$$

where $\Phi=\left(\frac{N_{a}}{N}\right)$

Specification (13) is used to compute the policy surprise on any day $k$ prior to a target change (i.e. $k<\tau$ ), except for two cases:

1. Kuttner (2001) argues that the market funds rate does not change until the day after a target change. Consequently, if the target change occurs on the last day of month, it would have no effect on that month's spot rate. In this case, the difference in one-month forward rates gives us the policy surprise since the onemonth rate reflects the expected average funds rate for the next month: ${ }^{12}$

$$
(\text { One }- \text { Month Rate })_{\tau}-(\text { One }- \text { MonthRate })_{k}=\Phi \underbrace{\left[\rho_{t}-E_{k}\left(\rho_{t}\right)\right]}_{\text {Unanticipded PolicyChangeasof dayk }}
$$

where $\Phi=\left(\frac{N}{N}\right)=1$

2. If the number of days in the forecast horizon is equal to (or greater than) the day of the month in which the target changes, we need to use the one-month forward rate from the previous month to assess market's expectations on day $k$. For instance, if we wish to compute the unanticipated policy change five days prior to a target change and if the target change occurs on the second day of the month, we need to look at the one-month forward rate on day $k=N-3$ of the previous month, and the spot rate on day 2 of the current month to compute the unanticipated policy change. That is:

\footnotetext{
${ }^{11}$ As it is noted by Kuttner (2001), this equation is only approximately correct since it does not account for the small change in the term premium on the day of the policy action, or the amount by which the effective funds rate deviates from the target on the day of the policy action, and the revisions in the expectation of future targeting errors. However, these effects are expected to be small, as also indicated by Lange, Sack, and Whitesell (2001).

${ }^{12}$ Admittedly, the assumption that the funds rate does not change on the day of a target announcement is inaccurate in an era where the anticipation effect is dominant. However, the funds rate does not completely reach the new target on the announcement day either, for the reasons that are discussed earlier in section 3 . Nevertheless, because the loss of information by relying on the one-month rate is relatively small (and proposing an alternative methodology that addresses these concerns is beyond the scope of this paper), we adopt Kuttner's methodology for end-of-month adjustments.
} 


$$
(\text { Spot Rate })_{\tau}-(\text { One }- \text { Month Rate })_{k}=\Phi \underbrace{\left[\rho_{t}-E_{k}\left(\rho_{t}\right)\right]}_{\text {Unanticipted PolicyChangeasof day } k}
$$

where $\Phi=\frac{N_{a}}{N}$

The methodology that we describe in this section allows us to estimate expectations of policy changes $k$ days prior to a target change, which generalizes Kuttner's method of computing anticipated policy actions on the day before the target change. ${ }^{13}$ This generalization provides us with an essential tool in testing the anticipation effect, as we can investigate how the level of anticipated changes as well as the revisions in anticipated policy influence financial markets prior to an announcement (or alternatively, prior to the complementary open market operations take place). Without this distinction, one may be unable to find an empirical relationship between changes in the funds rate and anticipated policy moves if interest rates only respond to revisions in expectations. This would be an especially valid argument if anticipated changes are incorporated into interest rates weeks in advance of an expected policy move.

In the remainder of this paper we present an empirical investigation of the anticipation and the announcement effects. In order to get a sense of transparency and anticipated policy actions in a historical perspective, we first analyze the time series behavior of policy surprises prior to and after February 1994. Our findings indicate that the unanticipated component of target changes decreased significantly in the post-1994 period, consistent with the general trend toward increased transparency. Next, we investigate whether improvements in the market's readings of future policy moves are reflected in interest rate adjustments. Throughout the entire sample period, there is strong evidence of interest rate adjustments prior to an anticipated policy move. However, very few adjustments take place after the announcement in the post-1994 period, as policy surprises declined significantly, providing strong evidence of the anticipation effect replacing the announcement effect. Consistent with this finding, the timing of open market operations have also been delayed until the second week following the target change. This is because the Trading Desk has the opportunity to wait for the

\footnotetext{
${ }^{13}$ Following Kuttner (2001), we adjust for two timing mismatches (12/18/1998 and 10/15/1998) where the target change took place after the futures market had closed. In order to deal with these occurrences, we treat the data as if the target change took place on the next day.
} 
market to adjust with new information, before it alters reserve pressures consistent with the new target.

\section{Empirical Analysis}

\section{Historical Behavior of Policy Surprises}

Our first exercise is to investigate how well the policy actions were anticipated prior to a target change. To that end, we first compute the unanticipated policy surprises on the day before a target change. Our sample covers the period from May 17, 1989 through September 5, 2001.

A priori, we expect the public's readings of Fed actions to improve significantly in the post-1994 period, consistent with the enhancements in transparency. Table 2 provides the descriptive statistics for unanticipated target changes. The sample is broken into two time periods, prior to and after February 1994. Each time period is further separated according to the direction of the policy action. The period prior to February 4, 1994 consists of 25 target easings. The period after February 1994 contains 14 policy tightenings and 13 policy easings. As we compare the sample means for these periods, we observe that unanticipated policy actions decreased significantly on average in the later sub-sample. In particular, while we reject the hypothesis of zero mean for the period before 1994, sample means are not significantly different than zero for the later sub-samples. Furthermore, the results from the Q-tests up to three lags suggest that policy surprises appear to be a Gaussian white noise process in the post-1994 period, whereas we reject that hypothesis for the pre-1994 sample.

Our next goal is to investigate the "evolutionary process" in the formation of expectations in the days leading to a target change. Intuitively, we would expect the unanticipated component to decline gradually, as the market continuously updates its expectations with incoming data. To that end, we compute the anticipated and

unanticipated target changes up to eleven days prior to a target change. Figure 3 presents our estimates for sample averages. The horizontal axis shows the forecast horizon. The first observation starts from -11 , which reads as "day $t$-11 prior to a target change that takes place on day $t$." Similarly, the last observation (-1) reads as "day $t-1$ prior to a target change that takes place on day $t$." Not surprisingly, the unanticipated component declines in a step-wise fashion in the period before 1994. While this overall pattern is 
also valid for the post-1994 period, the marginal step sizes are rather small. This is because the market is able to forecast the size of a target change more accurately and far earlier in this period, where additional information on each successive day is rather small (see Lange, Sack, Whitesell (2001) or Poole, Rasche, Thornton (2001) for analyses on how far in advance the market knew a policy action would be taken).

In order to provide a more exhaustive exploration of the time series properties of improvements in expectations, we look into the relationship between the unanticipated policy surprises and a time trend. Because there is not an obvious choice for the forecast horizon, we pick the end points and the middle point from the range of estimates that we have computed in Figure 3. Next, we regress the unanticipated policy surprise as a ratio of the actual target change onto a constant, a time trend (with an interactive dummy for the post-1994 period) and a dummy for inter-meeting policy changes for the post-1994 period. ${ }^{14}$ Because we solely focus on the days around target changes, the dependent variable is never zero and we can estimate this specification with ordinary least squares, as specified in equation (14):

$\frac{\text { Unanti }_{t-i}}{\Delta \rho_{t}}=\alpha+\beta_{1}\left(\right.$ Trend $\times$ Dummy $\left.y_{\text {Post-1994 }}\right)+\beta_{2}($ Dummy Intermeeting Change $)+u_{t}$

Equation (14) is estimated for the non-negative values of the dependent variable, which excludes forecast errors due to over-prediction. This way, we can interpret the lower values of the dependent variable as improvements in the accuracy of forecasts (or declines in the forecast error). If the public's assessments of the policy actions have indeed improved over time, then policy surprises should diminish in due course and display a negative relationship with a time trend. Table 3 exhibits the regression results. The sample period includes a total of 52 target changes. The sample size for each equation indicates the number of available observations, after taking out those

\footnotetext{
${ }^{14}$ The "inter-meeting" dummy tracks target changes that took place between the regularly scheduled FOMC meetings. Theoretically, while the Fed could still "surprise" the market by intervening at "unexpected times" in the period prior to1994, target changes were not as regularly scheduled around the FOMC meetings and it would be less trivial to determine when a "surprise action" took place. For that reason, we only have an inter-meeting dummy for the post-1994 period when the Federal Reserve started its practice of announcing target changes immediately after the FOMC meetings.
} 
observations where the predicted policy move was larger (in absolute value) than the size of the actual target change. Notice that the forecast error due to over-prediction increases over time, indicated by the gradual decline in the sample size as we approach the day of policy action. The significant negative coefficients associated with the trend variable provide evidence that policy surprises declined sharply through time in the post-1994 period. In other words, the public's readings of the Fed's policy actions improved drastically in the post-1994 period, which is reflected in expectations as early as ten days prior to a target change. Meanwhile, if the economic and financial conditions change rapidly, and the right policy move involves taking unexpected action, policy makers can do so through an inter-meeting announcement, since the unanticipated target change significantly increases whenever there is an inter-meeting move.

\section{Response of the Funds Rate to Expected Policy Changes}

After documenting evidence of improved policy expectations in a historical perspective, our next goal is to find out whether this structural change in expectations is reflected in the funds rate prior to a policy announcement. To that end, we regress changes in the funds rate onto anticipated policy actions and revisions in anticipated actions. In order to control for interest rate fluctuations that may arise due to changes in balance requirements, we add the volume of required operating balances (i.e. the sum of required reserves and required clearing balances) into the regression equation.

In order to capture the week of the maintenance period effects, we also add a dummy variable which controls for target changes that take place within the first week of the maintenance period. Everything else remaining the same, if interest rate changes arise from the motivation to exploit arbitrage opportunities, then the size of adjustments should be larger when the target change occurs earlier in the maintenance period. This is because the prospects for intertemporal substitution improve when there are more days until the end of the maintenance period, following the policy action. ${ }^{15}$ Meanwhile, banks have a general preference for holding higher excess reserves late in the period to avoid end-of-maintenance-period fluctuations. This incentive puts an upward pressure on reserve demand late in the maintenance period, independent of any anticipated policy move. Together, these two factors reinforce each other following a target cut, and

\footnotetext{
${ }^{15}$ I would like to thank Vincent Reinhart for bringing this point into my attention.
} 
generate a net increase in demand in the second week of the maintenance period.

However, they move in opposite directions following a policy tightening.

This set of independent variables leads to the following regression equation:

$$
F F R_{k}-F F R_{k-i}=\alpha+\beta_{1}(\text { anti } \Delta)_{k}+\beta_{2}(\text { revisions })_{k}+\beta_{3} \sum_{j=k-i}^{k} O B_{j}+\beta_{4} D_{M P}+\varepsilon_{k}
$$

where

$F F R_{k}$ is the federal funds rate on day $k$ of the maintenance period,

$O B_{k}$ is the volume of operating balances on day $k$ of the maintenance period,

and $D_{M P}$ is the dummy variable that is equal to one for the first week of the maintenance period.

Equation (15) is estimated for three different time frames, using business day data. First, we look at the five-day change covering days $t$-11 through $t-6$ prior to a target change. This period is indicated as "B-10" (ten days before) in the regression results in Table 4. Next, we look at the five-day change covering days $t-6$ through $t-2$ prior to a target change, indicated as "B-5" (five days before). Finally we look at the one-day change in the funds rate on the day before the actual change takes place, covering days $t$ 2 through $t-1$.

Table 4 highlights that none of the sample periods display any adjustments in the ten-day period prior to a target change. This could arise from limited intertemporal substitution opportunities across maintenance periods due to restrictions involved in carryover allowances. ${ }^{16}$ Alternatively, it could reflect firmer Desk behavior since worries against strict interest rate smoothing (due to instability generated by the funds rate fluctuations right before and after a target change) are not quite applicable in the ten-day period before a change.

In the period prior to February 1994, the funds rate adjusted to revisions in expectations in the five days prior to an anticipated policy action, where the magnitude of the adjustment is very close to its theoretical value of one $\left(\beta_{1}=1.26\right)$. This result is consistent with Orphanides's remark that the Desk may relieve its interest rate smoothing policy right before a target change in order to prevent larger fluctuations after the

\footnotetext{
${ }^{16}$ Certain rules define and limit the carryover privilege. The maximum allowable carryover is defined as the greater of either an amount $(\$ 50,000)$ or a percentage (four-percent) of the total requirement less the clearing balance allowance, if applicable.
} 
announcement. In other words, the Desk allows the funds rate to decline with anticipation prior to a policy easing, rather than "leaning against the wind." Similar adjustments are observed in the period after 1994. The funds rate adjusts within the week before a policy tightening, proportionally to the level of anticipated policy change $\left(\beta_{1}=1.10\right)$. Further adjustments take place on the day before the announcement $\left(\beta_{1}=0.96\right.$ ). While both of these samples exhibit interest rate adjustments in the five-day period prior to an anticipated policy move, the adjustments are not sensitive to whether the policy action takes place in the first or the second week of the maintenance period. This implies that banks rely on reserve adjustments as well as carryover transfers across maintenance periods interchangeably, in response to an anticipated policy action in the next week.

For the anticipated target easings, the decline in the funds rate on the day before a policy action becomes more noticeable as the size of revisions goes down. This is an interesting result in the sense that more than half of this sub-sample covers the easing cycle in 2001, a period when the market's ability to predict forthcoming policy moves improved dramatically. In this era, market rates incorporate future policy actions far in advance (see e.g. Lange, Sack and Whitesell (2001), Poole, Rasche and Thornton (2001)) and the funds rate declines significantly on the day before a widely anticipated policy cut. The greater the market confidence about the size of the anticipated policy action (i.e. the less negative the revisions in anticipated change), the larger is the size of the decline in the funds rate on the day before the policy move.

Different than the other sub-samples, the funds rate does not adjust with expectations in the week prior to an anticipated policy easing, even though the market confidence about the accuracy of expectations improved markedly in recent years. The likely factors that might contribute to this type of behavior are twofold: If it is a demanddriven behavior, it could reflect the reserve managers' reluctance to reduce reserve holdings in the week prior to a well anticipated policy easing, in order to avoid potential overdrafts in the presence of low reserve requirements. If it is a supply-driven behavior, however, it could reflect an increased strictness on the Desk's side in maintaining the funds rate at the current target. Alternatively, it could be a mixture of both factors. 
If the target cut occurs within the first week of the maintenance period, depository institutions have a wider window to move their reserve balances across the maintenance period. Ceteris paribus, this would indicate larger interest rate adjustments consistent with improved arbitrage opportunities. The positive sign associated with the maintenance period dummy for anticipated target cuts indicates that the funds rate declines less on the day before the anticipated easing, if the policy action occurs in the first half of the maintenance period. This result could arise from lack of variation in a small sample, as there are only four policy easings that took place within the first week of the maintenance period (out of 12 policy easings since February 1994). Alternatively, it could arise from the reluctance of reserve managers in reducing reserve holdings in the first week of the maintenance period, for the reasons discussed in the previous paragraph. If this is the case, then demand would decline less prior to a target cut when the policy easing occurs in the first week of the maintenance period. An alternative factor could be related to banks' preference for holding higher excess reserves late in the maintenance period. If the Desk pursues a stricter policy within the first week of the maintenance period, but follows a more lenient approach in the second week to avoid end-of-maintenance-period fluctuations, demand shifts would be offset more aggressively within the first week, and hence the funds rate would decline less prior to an anticipated easing.

\section{Open Market Operations After a Target Change}

The anticipation effect theory indicates that the Trading Desk adjusts reserve pressures promptly after a target change so that the credibility of the policy

announcement is well established. While the magnitude of necessary reserve adjustments is the same under the traditional liquidity effect and the anticipation effect channels, the timing of these operations may differ. The liquidity effect theory necessitates an immediate action by the Trading Desk, since open market operations are the only way to inform the market about the new target level. In contrast, under the anticipation effect the Trading Desk does not need to act immediately, since the market is already informed about the new target level, following the policy announcement. More specifically, the Desk can postpone its action until the demand for reserves returns to its initial level (i.e. from $D_{2}$ to $D_{0}$ in Figure 1). 
In order to provide an empirical analysis of open market operations after a target change, we estimate equation (16):

$$
\Delta \rho_{t}=\alpha+\beta_{1} \sum_{j=t}^{m}(\text { Easing Operations })_{j}+\beta_{2} \sum_{j=t}^{m}(\text { Draining Operations })_{j}+\beta_{3} \sum_{j=t}^{m} O B_{j}+\varepsilon_{t}
$$

In the above specification, Easing Operations are open market purchases of bonds and Treasury securities whereas Draining Operations mostly indicate open market sales. Based on the duration of each transaction, open market data can be classified as permanent, temporary, and overnight operations, which can then be grouped according to whether the operation injects or drains liquidity. For the purposes of equation (16), we define Easing Operations as the sum of overnight repurchase agreements, term repurchase agreements, and domestic outright purchases of Treasury bills and coupon securities, which all add to reserves. Draining Operations are defined as the sum of overnight matched sale purchase agreements, term matched sale purchase agreements, and domestic outright sales of Treasury bills and coupon securities (see Feinman (1993) or Edwards (1997) for a detailed discussion of dfferent types of open market operations). Following Demiralp and Jordá (2000), we also include maturing term repurchase agreements that spill over multiple maintenance periods in this category because these operations have a draining effect on reserves at their expiration. The data is further adjusted to obtain the reserve impacts of each transaction, following the transformation technique described by Feinman (1993). We exclude operations based on foreign assets since the Desk does not use foreign securities for domestic operations.

Equation (16) allows us to measure the relationship between target changes and open market operations, after controlling for any reserve adjustments that are induced by fluctuations in reserve requirements. Notice that both easing and draining operations can be used to alter reserve pressures following a target change. In particular, while open market purchases are the direct means to ease reserve pressures in the market, the Desk can also provide the same "easing effect" indirectly, by reducing the size of sale operations to reinforce a target cut. In order to control for these alternatives, we include both types of operations in the specification. Similar to the previous specification, we estimate equation (16) at different time intervals: on the day of a target change (day $t$ ), 
the day after the target change (day $t+1$ ), five-day period from day $t+1$ through $t+6$, and the five-day period from day $t+6$ through $t+10$.

Table 5 presents the estimation results from this exercise. ${ }^{17}$ In the period before 1994, significant adjustments in open market purchases were made immediately following the target change. In particular, in order to achieve, say, a 25 basis points decrease in the target, the Desk increased maintenance period average level of reserves by $\frac{0.25}{0.04}=\$ 6.25$ billion on the day of policy easing. ${ }^{18}$ Supplementary operations (adding to period-average level of reserves about $\frac{0.25}{0.02}=\$ 1.25$ billion) were needed within the first week following a target change. Insignificant coefficients for the rest of the time frames indicate that the Desk enforced the bulk of the necessary reserve adjustments on the first day.

In contrast, when we look at the policy tightenings in the post-1994 period, we note that open market operations were not significant until the ten-day period following the target change. Clearly, the Desk allows market rates to adjust with the announcement in the week following the policy action in this period. In the second week, the Desk relies on both types of operations to drain reserves. Specifically, in order to provide, say, a 25 basis points rise in interest rates, the Desk sells securities that drains period-average level of reserves by $\frac{0.25}{0.04}=\$ 6.25$ billion, and reduces purchases that drain period-average reserves by $\frac{0.25}{0.05}=\$ 5$ billion. Reliance on this second tool is especially important in the post-1994 period because the Desk has developed a tendency to place itself in a position of needing to add reserves on a temporary basis. This is because the Desk does not want to drain reserves during periods where low operating balances might lead to late day firmness in the money market and also because there has been an increasing demand for currency over a historical time frame (see e.g. Cohen (1997), Hilton (1999)). The results for post-1994 policy easings further reinforce these findings where the Desk reduces

\footnotetext{
${ }^{17}$ Open market operations are expressed in millions of dollars.

${ }^{18}$ Note that a $\$ 6.25$ billion increase in reserves is equivalent to an overnight purchase of $\$ 6.25 \times 14=\$ 87.5$ billion, conducted on a Monday (or any other weekday other than Friday).
} 
draining operations drastically within the two weeks following a target cut. Our results also indicate that required operating balances increase significantly in the five-day period following a target cut in the post-1994 period. In particular, a full percentage point decrease in the federal funds rate target is associated with a $\$ 2.93$ billion increase in operating balances. This may arise from an increase in liquid deposits due to a decline in the opportunity cost of holding money in the presence of lower interest rates.

\section{Term Structure prior to a Target Change}

In the remainder of this paper, we analyze how the rest of the term rates react to target changes prior to and following a policy move. To that end, we first investigate the response of term rates to anticipated policy actions prior to a policy move. Equation (17) is estimated for a wide maturity of Treasury securities: 3-month, 6-month Treasury bills, 2-year, 3-year, 5-year, 7-year, and 10-year Treasury notes, and 30-year Treasury bonds:

$$
T R_{k}-T R_{k-i}=\alpha+\beta_{1}(\text { anti } \Delta)_{k}+\beta_{2}(\text { revisions })_{k}+\varepsilon_{k}, \quad k<t
$$

Here, $T R_{k}$ denotes the relevant rate on the Treasury security on day $k$, where $k<t$

( i.e. prior to a target change that takes place on day $t$ ), obtained from the Federal Reserve H.15 release.

Table 6 presents the regression results. The results display an overall coherence in the behavior of the funds market and the rest of the financial markets. Recall from Table 4 that in the period prior to 1994, the funds rate adjusted to revisions in expectations in the week before an anticipated easing. Treasury rates adjust in the same manner to revisions in expectations. However, the adjustments take place as early as two weeks prior to the anticipated change and they carry on until the day before the policy move.

The overall increase in the values of $R^{2}$ for the post-1994 tightenings (relative to pre-1994 period) provide strong evidence of the increasing role of expectations in the last decade. For this sample, term rates appear to adjust with anticipated target changes in the ten days prior to a policy move. Further adjustments with revisions take place in the following week. Meanwhile long-term maturities (three years and more) decline within the week prior to an anticipated tightening. 
As for the post-1994 easings, short-term rates respond to anticipated or revised target changes positively for shorter maturities, although the explanatory power is not very strong. Long-term maturities do not respond to any anticipated policy change. We believe that this result arises from the fact that most of this sample corresponds the easing cycle in 2001, where the gradual trend towards transparency has reached its peak. In this environment, it is more likely to expect that term rates incorporate future policy changes at least a few months in advance, consistent with the autoregressive nature of policy changes and improvements in transparency (see Lange, Sack and Whitesell (2001), Poole, Rasche and Thornton (2001)).

\section{Term Structure after a Target Change}

Our final test investigates the term structure following a target change. To that end, we estimate equation (18) for the same set of Treasury securities described in equation (17).

$$
T R_{t+i}-T R_{t}=\alpha+\beta_{1}(\text { anti } \Delta)_{t}+\beta_{2}(\text { unanti } \Delta)_{t}+\varepsilon_{t}
$$

$T R_{t+i}$ indicates the relevant rate on the Treasury security on day $t+i$ (i.e. $i$ days after the target change that takes place on day $t$ ).

Equation (18) is similar in structure to Cook and Hahn (1989) and Kuttner (2001) where the change in the term rate is regressed on the two components of a target change. Table 7 exhibits the estimation results. Once again, the results are highly consistent with the anticipation effect. Most rates respond to anticipated and unanticipated target changes on the day of the policy action in the period prior to 1994. Kuttner (2001) reckons that the anticipated component may be significant because it may release unanticipated information regarding future policy moves. Poole, Rasche and Thornton (2001) take an alternative view and show that this result disappears once they control for discount rate changes. The authors highlight the fact that there were very few occasions where the funds rate target and the discount rate were changed simultaneously in the pre1994 period. As a result, the market received additional "unanticipated" information when the discount rate was changed together with the funds rate target.

Another common finding in the literature, which is also supported by our results is that the term rate response declines as the maturity lengthens. This behavior may 
reflect the market's perception that policy changes prevail for a relatively short period of time, after which the policy cycle reverses itself.

In the post-1994 period, very few changes take place due to the anticipated component, since most adjustments occur prior to the announcement consistent with our earlier results. Note that for all sub-samples, the coefficient values associated with the unanticipated target changes are generally less than one. Kuttner (2001) describes this empirical observation with his "timing hypothesis." Accordingly, if the target changes take place at regular FOMC meetings, then the market's response is weaker, as long as these changes follow the same general direction of previous policy moves. This is because the forecast error associated with these changes may indicate a misprediction regarding the timing of the target change, although that policy action may have been widely expected to occur sometime in near future. Since the majority of our sample consists of target changes that took place at regularly scheduled meetings (there are only 4 inter-meeting changes in the post-1994 period), the timing hypothesis seems to be the underlying factor that accounts for our results.

Following a policy tightening, short-term maturities increase proportionally to the unanticipated component on the day of announcement in the post-1994 period. Maturities that are seven years or longer exhibit a negative response in the five-day period following a target change, which reverses itself almost completely in the following week. For the post-1994 period of policy easings, short-term rates respond only to the unanticipated component on the day of the announcement. Meanwhile the thirty-year rate responds negatively to the unanticipated component, which could arise from a Fisher-type response due to longer-term concerns regarding the effects of monetary policy on future inflation rates.

\section{Conclusion}

This paper has explored the manner in which recent institutional changes in the Federal Reserve's operating procedures altered the traditional monetary transmission mechanism. In particular, we focused on two elements: the transmission of policy expectations to the overnight rates, and the transmission of policy expectations to the term structure. The conventional view relies on the liquidity effect to explain how open market operations affect the overnight rate, without considering the role of anticipated 
policy moves in affecting interest rates. In this paper, we highlighted the historical steps towards transparency, which created an essential link between policy expectations and financial markets. We expanded the existing theoretical literature to derive testable implications of the anticipation effect.

Our empirical results provide strong evidence that by maintaining a persistent trend towards transparency and gradualism, the Federal Reserve has drastically improved its ability to control interest rates in the last decade. By affecting policy expectations prior to a policy move, the Fed can (and does) not only influence interest rates before the actual policy action but it also "surprises" the markets by an unanticipated policy announcement whenever an immediate intervention is necessary. As transparency enhances credibility, the markets take the policy announcement of the change in the stance of policy at its face value and respond immediately, without waiting for accompanying reserve changes that follow the announcement. This instantaneous market response further stimulates the efficiency in policy making since the most immediate goals of the target change are put into action without any delay. 
Figure 1. Reserves Market with a Target Raise on Day $t$ of the Maintenance Period

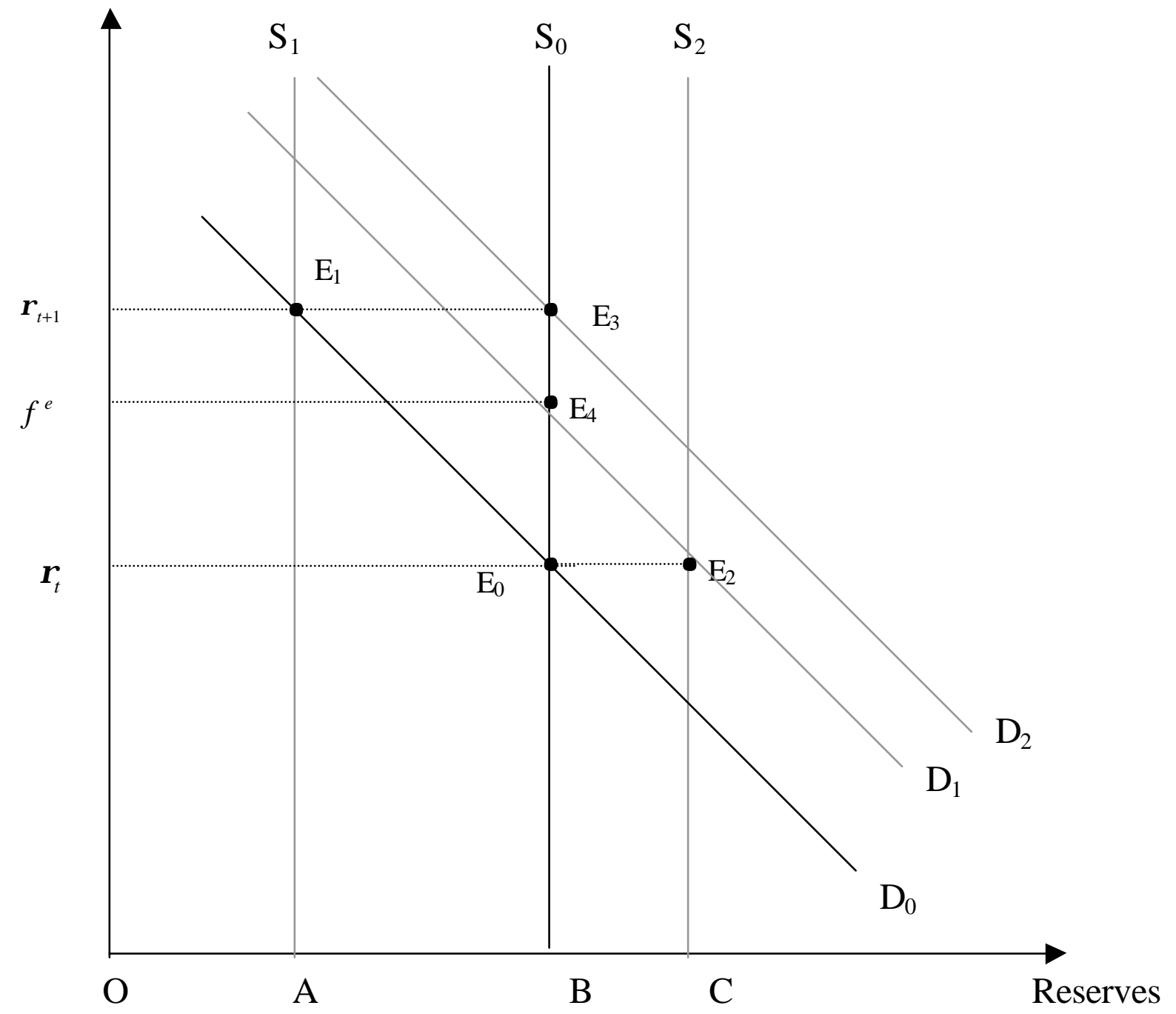

Table 1

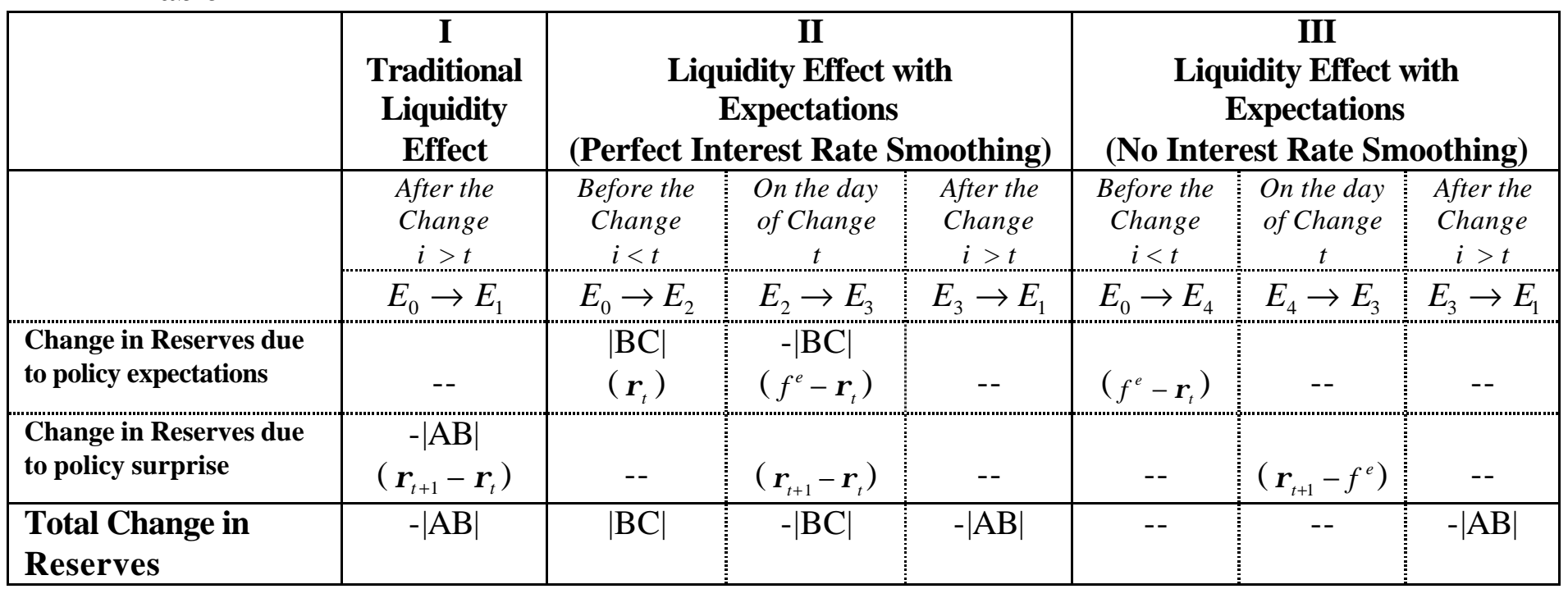


Figure 2. Formation of Expectations in the Reserves Market

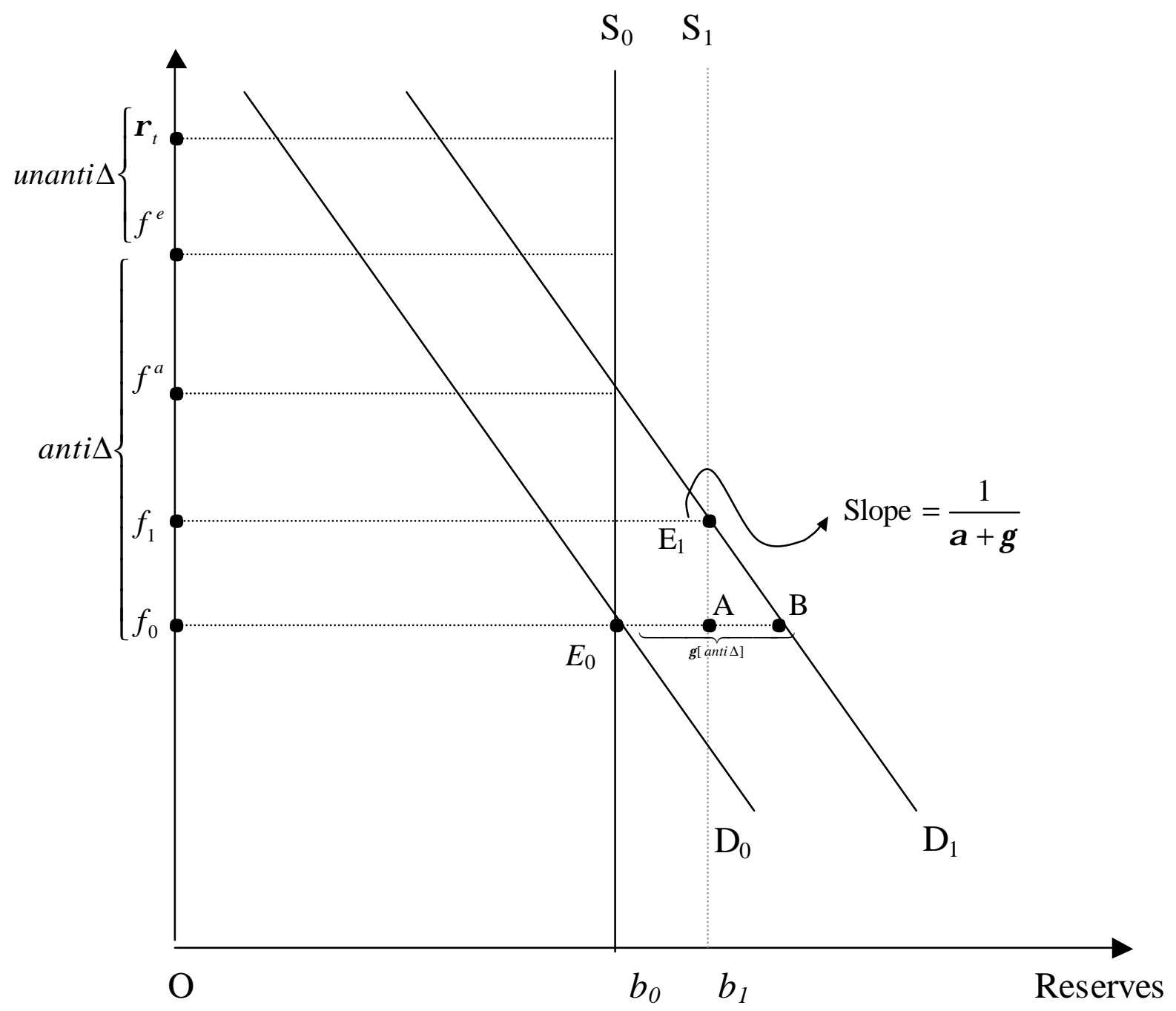


Figure 3. Evolution of Expected Policy Actions
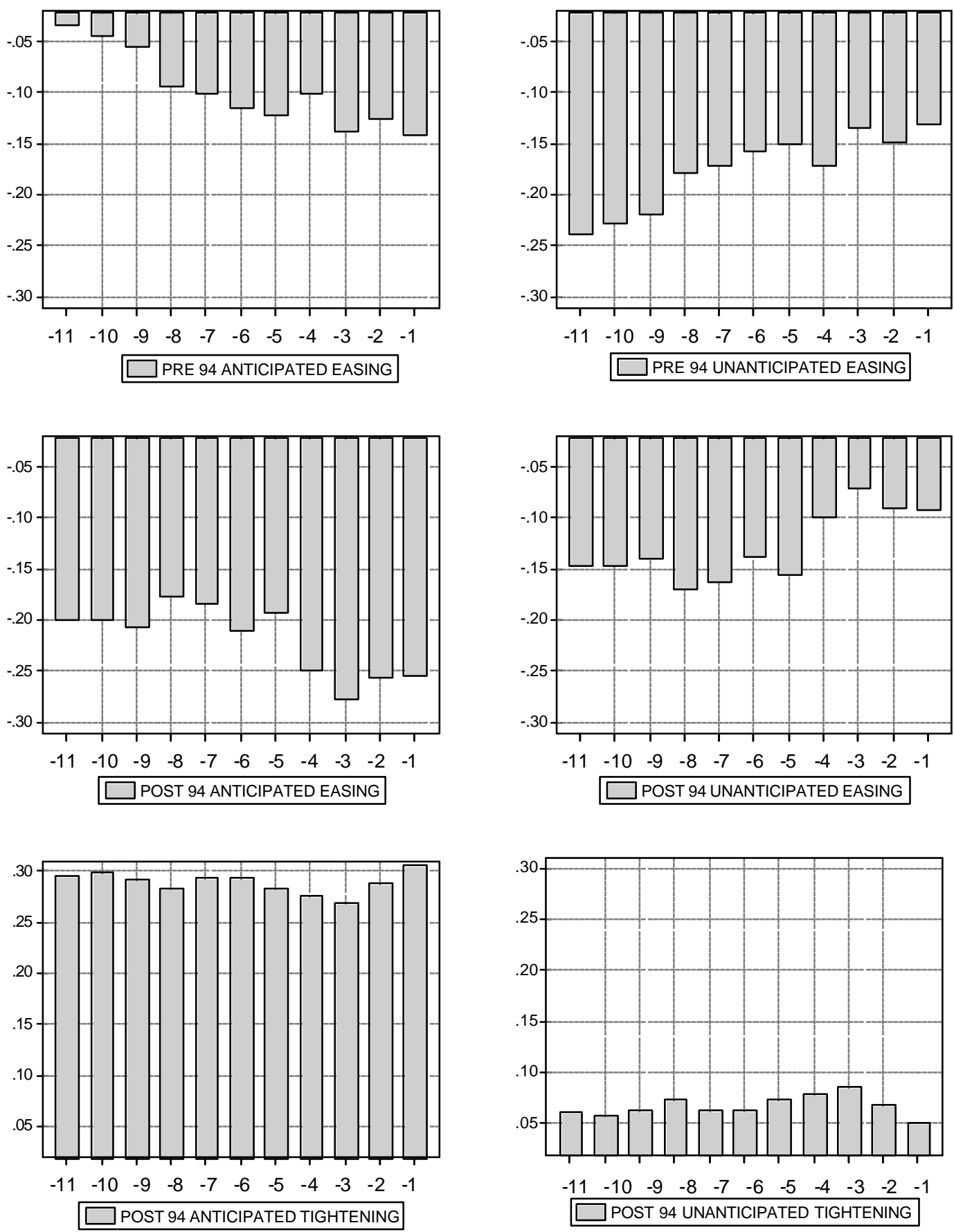

The vertical axis measures the anticipated and unanticipated target changes as an average over the sample period. The horizontal axis indicates the day in which expectations are formed. For example, the first observation (-11) reads as "day $t-11$ prior to a target change that takes place on day $t$." Similarly, the last observation (-1) reads as day $t-1$ prior to a target change that takes place on day $t . "$ 
Table 2. Descriptive Statistics of Unanticipated Target Changes ${ }^{19}$

\begin{tabular}{l|c|c|c}
\hline \hline & $\begin{array}{c}\text { Pre February 1994 } \\
\text { (Policy Easings) }\end{array}$ & $\begin{array}{c}\text { Post February 1994 } \\
\text { (Policy Tightenings) }\end{array}$ & $\begin{array}{c}\text { Post February 1994 } \\
\text { (Policy Easings) }\end{array}$ \\
\hline Mean & -0.1307 & 0.0513 & -0.092060 \\
Probability $\left(H_{0}:\right.$ Mean $\left.=0\right)$ & 0.000 & 0.019 & 0.065 \\
Median & -0.1378 & 0.0569 & -0.046154 \\
Std. Dev. & 0.1157 & 0.0720 & 0.164024 \\
Skewness & -0.1588 & -0.1634 & -1.134845 \\
Kurtosis & 2.0354 & 1.5608 & 3.171988 \\
Jarque-Bera & 1.0743 & 1.2705 & 2.806415 \\
Probability $\left(H_{0}: \varepsilon_{t} \sim N(\mu, \sigma)\right)$ & 0.5844 & 0.5298 & 0.245807 \\
Ljung-Box Q-statistic $($ Lag 1$)$ & 3.0608 & 0.8185 & 0.798 \\
Probability $\left(H_{0}:\right.$ Autocorrelation & \\
Ljung-Box Q-statistic $($ Lag 2$)$ & 0.080 & 0.366 & 0.372 \\
Probability $\left(H_{0}:\right.$ Autocorrelation $\left._{2}=0\right)$ & 7.9556 & 0.8298 & 3.9423 \\
Ljung-Box Q-statistic $($ Lag 3$)$ & 0.019 & 0.660 & 0.139 \\
Probability $\left(H_{0}:\right.$ Autocorrelation $\left._{3}=0\right)$ & 8.2694 & 1.5007 & 5.6239 \\
\hline \hline
\end{tabular}

Table 3. The Time Series Pattern of Unanticipated Target Changes

$\frac{\text { Unanti }_{t-i}}{\Delta \rho_{t}}=\alpha+\beta_{1}($ Trend $\times$ Dummy Post-1994 $)+\beta_{2}\left(\right.$ Dummy $\left._{\text {Intermeeting Change }}\right)+u_{t}$

\begin{tabular}{|c|c|c|c|c|c|}
\hline \multirow[b]{2}{*}{ Time Period } & \multirow[b]{2}{*}{ Sample Size } & \multicolumn{4}{|c|}{ Explanatory Variables } \\
\hline & & $\mathrm{R}^{2}$ & Constant & Trend*Dummy_Post-1994 & Dummy_Inter-meeting \\
\hline \multirow{2}{*}{ B-10 } & \multirow{2}{*}{46} & & 0.99 & -0.02 & 0.51 \\
\hline & & 0.22 & $(7.37)^{* * *}$ & $(-3.48)^{* *}$ & (1.26) \\
\hline \multirow{2}{*}{ B-5 } & \multirow{2}{*}{44} & & 0.78 & -0.01 & 0.24 \\
\hline & & 0.23 & $(8.53)^{* *}$ & $(-3.50) * *$ & $(1.01)$ \\
\hline \multirow{2}{*}{ B-1 } & \multirow[b]{2}{*}{43} & & 0.63 & -0.01 & 0.56 \\
\hline & & 0.35 & $(10.23)^{* *}$ & $(-4.10)^{* *}$ & $(3.41)^{* *}$ \\
\hline \multirow{2}{*}{ D } & \multirow{2}{*}{42} & & 0.53 & -0.01 & 0.57 \\
\hline & & 0.32 & $(8.88) * *$ & $(-3.62) * *$ & $(3.53) * *$ \\
\hline
\end{tabular}

The first column reports the time period in each equation where B-10, B-5, and B-1 refer to the ten-day, five-day, and one-day periods prior to a target change and $\mathrm{D}$ refers to the day of the target change respectively.

t-ratios are in parenthesis. $* *(*)$ indicates significance at the $95 \%(90 \%)$ confidence level.

\footnotetext{
${ }^{19}$ The first sub-sample (May 18, 1989 to February 4, 1994) includes 25 policy easings. The Second subsample (February 4, 1994-September 5, 2001) includes 14 policy tightenings. The third sub-sample (February 4, 1994-September 5, 2001) includes 13 policy easings.
} 
Table 4. Changes in the Funds Rate in the days prior to a Target Change

$$
F F R_{k}-F F R_{k-i}=\alpha+\beta_{1}(\text { anti } \Delta)_{k}+\beta_{2}(\text { revisions })_{k}+\beta_{3} \sum_{j=k-i}^{k} O B_{j}+D_{M P}+\varepsilon_{t}
$$

Pre-1994, Before a Policy Easing

\begin{tabular}{l|cccccc}
\hline \hline & \multicolumn{6}{|c}{ Explanatory Variables } \\
\cline { 2 - 7 } Time Period & $\mathrm{R}^{2}$ & Constant & $\begin{array}{c}\text { Anticipated } \\
\text { Change }\end{array}$ & $\begin{array}{c}\text { Revisions in } \\
\text { Expectations }\end{array}$ & $\begin{array}{c}\text { Operating } \\
\text { Balances }\end{array}$ & Dummy \\
\hline \multirow{2}{*}{ B-10 } & & 0.67 & -0.85 & 0.56 & -3.31 & -0.27 \\
& 0.22 & $(1.08)$ & $(-1.44)$ & $(1.29)$ & $(-1.02)$ & $(-1.47)$ \\
\hline \multirow{2}{*}{ B-5 } & & -0.05 & -0.28 & 1.26 & 0.29 & -0.22 \\
& 0.19 & $(-0.10)$ & $(-0.44)$ & $(2.10)^{* *}$ & $(0.10)$ & $(-1.30)$ \\
\hline \multirow{2}{*}{ B-1 } & & 0.31 & -0.85 & 0.88 & -12.48 & -0.06 \\
& 0.09 & $(0.60)$ & $(-1.13)$ & $(0.60)$ & $(-0.72)$ & $(-0.40)$ \\
\hline \hline
\end{tabular}

Post-1994, Before a Policy Tightening

\begin{tabular}{l|cccccc}
\hline \hline & \multicolumn{6}{|c}{ Explanatory Variables } \\
\cline { 2 - 7 } Time Period & $\mathrm{R}^{2}$ & Constant & $\begin{array}{c}\text { Anticipated } \\
\text { Change }\end{array}$ & $\begin{array}{c}\text { Revisions in } \\
\text { Expectations }\end{array}$ & $\begin{array}{c}\text { Operating } \\
\text { Balances }\end{array}$ & Dummy \\
\hline \multirow{2}{*}{ B-10 } & & 0.02 & -0.53 & 0.46 & 0.97 & -0.17 \\
& 0.36 & $(0.13)$ & $(-1.58)$ & $(0.89)$ & $(0.86)$ & $(-1.43)$ \\
\hline \multirow{2}{*}{ B-5 } & & -0.08 & 1.10 & -0.20 & -0.40 & 0.16 \\
& 0.45 & $(-0.33)$ & $(2.25)^{* *}$ & $(-0.30)$ & $(-0.25)$ & $(1.04)$ \\
\hline \multirow{2}{*}{ B-1 } & & -0.32 & 0.96 & 0.05 & 7.27 & -0.06 \\
& 0.47 & $(-1.59)$ & $(2.55)^{* *}$ & $(0.03)$ & $(1.03)$ & $(-0.54)$ \\
\hline \hline
\end{tabular}

Post-1994, Before a Policy Easing

\begin{tabular}{l|cccccc}
\hline \hline & \multicolumn{6}{|c}{ Explanatory Variables } \\
\cline { 2 - 7 } Time Period & $\mathrm{R}^{2}$ & Constant & $\begin{array}{c}\text { Anticipated } \\
\text { Change }\end{array}$ & $\begin{array}{c}\text { Revisions in } \\
\text { Expectations }\end{array}$ & $\begin{array}{c}\text { Operating } \\
\text { Balances }\end{array}$ & Dummy \\
\hline \multirow{2}{*}{ B-10 } & & -0.55 & -1.26 & 0.72 & -0.16 & 0.30 \\
& 0.22 & -0.83 & -1.12 & 0.51 & -0.03 & 0.96 \\
\hline \multirow{2}{*}{ B-5 } & & -0.43 & 0.29 & 0.30 & 6.25 & 0.24 \\
& 0.31 & -0.57 & 0.27 & 0.26 & 0.97 & 0.70 \\
\hline \multirow{2}{*}{ B-1 } & & -0.80 & 0.61 & -1.92 & 50.17 & 0.76 \\
& 0.77 & $(-1.81)$ & $(1.04)$ & $(-2.10)^{*}$ & $(2.44)^{* *}$ & $(3.85)^{* *}$ \\
\hline \hline
\end{tabular}

Open market operations are measured in millions of dollars.

t-ratios are in parenthesis. $* *(*)$ indicates significance at the $95 \%(90 \%)$ confidence level. 
Table 5. Open Market Operations in the days after a Target Change

$$
\Delta \rho_{t}=\alpha+\beta_{1} \sum_{j=t}^{m}(\text { Easing Operations })_{j}+\beta_{2} \sum_{j=t}^{m}(\text { Draining Operations })_{j}+\beta_{3} \sum_{j=t}^{m} O B_{j}+\varepsilon_{t}
$$

Pre-1994, After a Policy Easing

\begin{tabular}{l|ccccc}
\hline \hline \multirow{2}{*}{ Time Period } & \multicolumn{5}{|c}{ Explanatory Variables } \\
\cline { 2 - 6 } & $\mathrm{R}^{2}$ & Constant & $\begin{array}{l}\text { Easing } \\
\text { Operations }\end{array}$ & $\begin{array}{l}\text { Draining } \\
\text { Operations }\end{array}$ & $\begin{array}{l}\text { Operating } \\
\text { Balances }\end{array}$ \\
\hline D & & -0.33 & -0.04 & 0.05 & 2.11 \\
& 0.21 & $(-3.15)^{* *}$ & $(-1.80)^{*}$ & $(0.73)$ & $(0.66)$ \\
\hline A-1 & & -0.42 & 0.04 & 0.05 & 4.35 \\
& 0.09 & $(-3.47)^{* *}$ & $(0.54$ & $(0.70)$ & $(1.12)$ \\
\hline A-5 & & -0.59 & -0.02 & -0.03 & 1.95 \\
& 0.34 & $(-5.05)^{* *}$ & $(-2.40)^{* *}$ & $(-1.10)$ & $(2.91)^{* *}$ \\
\hline A-10 & \multicolumn{7}{c}{-0.52} & -0.01 & 0.00 & 1.39 \\
& 0.17 & $(-3.76)^{* *}$ & $(-0.89$ & $(0.01)$ & $(1.79)^{*}$ \\
\hline \hline
\end{tabular}

Post-1994, After a Policy Tightening

\begin{tabular}{l|ccccc}
\hline \hline \multirow{2}{*}{ Time Period } & \multicolumn{5}{|c}{ Explanatory Variables } \\
\cline { 2 - 6 } & $\mathrm{R}^{2}$ & Constant & $\begin{array}{l}\text { Easing } \\
\text { Operations }\end{array}$ & $\begin{array}{l}\text { Draining } \\
\text { Operations }\end{array}$ & $\begin{array}{l}\text { Operating } \\
\text { Balances }\end{array}$ \\
\hline $\mathrm{D}$ & & 0.25 & -0.01 & -- & 4.60 \\
& 0.06 & $(1.77)$ & $(-0.03)$ & -- & $(0.79)$ \\
\hline A-1 & & 0.28 & 0.13 & -0.03 & 1.35 \\
& 0.22 & $(1.77)$ & $(1.44)$ & $(-0.55)$ & $(0.23)$ \\
\hline A-5 & & 0.38 & -0.01 & 0.01 & 0.16 \\
& 0.11 & $(1.54)$ & $(-0.58)$ & $(0.24)$ & $(0.12)$ \\
\hline A-10 & & 0.50 & -0.05 & 0.04 & -0.25 \\
& 0.47 & $(2.91)^{* *}$ & $(-2.59) * *$ & $(2.62)^{* *}$ & $(-0.27)$ \\
\hline \hline
\end{tabular}


Table 5 (Continued)

\section{Post-1994, After a Policy Easing}

\begin{tabular}{l|ccccc}
\hline \hline \multirow{2}{*}{ Time Period } & \multicolumn{5}{|c}{ Explanatory Variables } \\
\cline { 2 - 7 } & $\mathrm{R}^{2}$ & Constant & $\begin{array}{l}\text { Easing } \\
\text { Operations }\end{array}$ & $\begin{array}{l}\text { Draining } \\
\text { Operations }\end{array}$ & $\begin{array}{l}\text { Operating } \\
\text { Balances }\end{array}$ \\
\hline D & & -0.39 & -0.01 & -0.48 & 4.59 \\
& 0.46 & $(-2.73)^{* *}$ & $(-0.08)$ & $(-2.47)^{* *}$ & $(0.60)$ \\
\hline A-1 & & -0.36 & -0.03 & 0.01 & 1.80 \\
& 0.09 & $(-2.01)^{*}$ & $(-0.66)$ & $(0.22)$ & $(0.26)$ \\
\hline A-5 & & -0.68 & 0.01 & -0.01 & 2.93 \\
& 0.39 & $(-3.79)^{* *}$ & 0.79 & -0.37 & $(2.18)^{*}$ \\
\hline A-10 & & -0.16 & -0.02 & -0.03 & -0.20 \\
& 0.55 & $(-0.70)$ & $(-1.19)$ & $(-2.54)^{* *}$ & $(-0.14)$ \\
\hline \hline
\end{tabular}

The time periods D, A-1, A-5, A-10 refer to the day of, one-day after, five days after and ten days after a target change respectively.

"Easing Operations" are defined as the sum of overnight repurchase agreements, term repurchase agreements, and domestic outright purchases of Treasury bills and coupon securities.

"Draining Operations" are defined as the sum of overnight matched sale purchases, term matched sale purchases, and domestic outright sales of Treasury bills and coupon securities. In addition to these sale operations, we include term repurchase agreements that expire in that particular maintenance period as these operations have a draining effect on reserves.

Data for open market operations and operating balances are in billions of dollars.

t-ratios are in parenthesis. $* *(*)$ indicates significance at the $95 \%(90 \%)$ confidence level. 
Table 6. Term Structure Prior to a Change ${ }^{20}$

$T R_{k}-T R_{k-i}=\alpha+\beta_{1}(\text { anti } \Delta)_{k}+\beta_{2}(\text { revisions })_{k}+\varepsilon_{t}$

\section{Pre-1994, Before a Policy Easing}

\begin{tabular}{|c|c|c|c|c|c|}
\hline & \multirow[b]{2}{*}{ Time Period } & & \multicolumn{3}{|c|}{ Explanatory Variables } \\
\hline & & $\mathrm{R}^{2}$ & Constant & $\begin{array}{c}\text { Anticipated } \\
\text { Change }\end{array}$ & $\begin{array}{l}\text { Revisions in } \\
\text { Expectations }\end{array}$ \\
\hline \multirow{3}{*}{ TB3 } & B-10 & 0.29 & 0.02 & -0.01 & $0.36^{* *}$ \\
\hline & B-5 & 0.35 & -0.05 & 0.05 & $0.50 * *$ \\
\hline & B-1 & 0.12 & -0.02 & -0.06 & 0.27 \\
\hline \multirow{3}{*}{ TB6 } & B-10 & 0.28 & $\begin{array}{l}-0.01 \\
\end{array}$ & $\begin{array}{l}-0.03 \\
\end{array}$ & $0.39 * *$ \\
\hline & B-5 & 0.46 & $-0.07 * *$ & -0.01 & $0.62 * *$ \\
\hline & B-1 & 0.20 & -0.02 & -0.09 & $0.44 * *$ \\
\hline \multirow{3}{*}{ ТВ2y } & B-10 & 0.31 & -0.04 & -0.06 & $0.42 * *$ \\
\hline & B-5 & 0.38 & $-0.07 *$ & 0.02 & $0.77 * *$ \\
\hline & B-1 & 0.21 & -0.01 & -0.03 & $0.51 * *$ \\
\hline \multirow{3}{*}{ TB3y } & B-10 & 0.32 & -0.03 & -0.02 & $0.42 * *$ \\
\hline & B-5 & 0.40 & $-0.08^{*}$ & 0.00 & $0.73 * *$ \\
\hline & B-1 & 0.15 & -0.01 & -0.01 & $0.36^{*}$ \\
\hline \multirow{3}{*}{ TB5y } & B-10 & 0.34 & -0.03 & -0.08 & $0.43 * *$ \\
\hline & B-5 & 0.36 & -0.05 & 0.09 & $0.64 * *$ \\
\hline & B-1 & 0.09 & 0.00 & 0.08 & 0.23 \\
\hline \multirow{3}{*}{ TB7y } & B-10 & 0.39 & -0.01 & -0.07 & $0.45^{* *}$ \\
\hline & B-5 & 0.34 & -0.03 & 0.13 & $0.53 * *$ \\
\hline & B-1 & 0.10 & 0.00 & 0.08 & 0.16 \\
\hline \multirow{3}{*}{ TB10y } & B-10 & 0.41 & -0.01 & -0.07 & $0.45 * *$ \\
\hline & B-5 & 0.27 & -0.03 & 0.13 & $0.45 * *$ \\
\hline & B-1 & 0.10 & 0.01 & 0.11 & 0.16 \\
\hline \multirow{3}{*}{ TB30y } & B-10 & 0.46 & -0.01 & -0.10 & $0.46^{* *}$ \\
\hline & B-5 & 0.21 & 0.00 & 0.15 & $0.33 * *$ \\
\hline & B-1 & 0.13 & 0.02 & $0.15^{*}$ & 0.07 \\
\hline
\end{tabular}

\section{Post-1994, Before a Policy Tightening}

\begin{tabular}{ll|cccc}
\hline \hline & & \multicolumn{3}{|c}{ Explanatory Variables } \\
& Time Period & $\mathrm{R}^{2}$ & Constant & $\begin{array}{c}\text { Anticipated } \\
\text { Change }\end{array}$ & $\begin{array}{c}\text { Revisions in } \\
\text { Expectations }\end{array}$ \\
\hline \multirow{3}{*}{ TB3 } & B-10 & 0.62 & -0.02 & $0.39^{* *}$ & 0.29 \\
& B-5 & 0.62 & $0.12^{* *}$ & -0.18 & $0.52^{* *}$ \\
& B-1 & 0.10 & 0.03 & 0.00 & 0.32 \\
\hline \multirow{2}{*}{ TB6 } & B-10 & 0.58 & 0.00 & $0.39^{* *}$ & 0.26 \\
& B-5 & 0.69 & $0.09^{* *}$ & -0.12 & $0.60^{* *}$ \\
& B-1 & 0.14 & 0.03 & -0.02 & 0.27 \\
\hline
\end{tabular}

${ }^{20}$ In order to present the estimation results in a compact form, we only report the coefficient estimates and indicate their significance as a superscript. The equations that are reported in the first column refer to three-month, six-month Treasury bills and two-year through thirty-year Treasury securities respectively. ** (*) indicates significance at the $95 \%(90 \%)$ confidence level. 
Post-1994, Before a Policy Tightening (Continued)

\begin{tabular}{|c|c|c|c|c|c|}
\hline & \multirow[b]{2}{*}{ Time Period } & & \multicolumn{3}{|c|}{ Explanatory Variables } \\
\hline & & $\mathrm{R}^{2}$ & Constant & $\begin{array}{c}\text { Anticipated } \\
\text { Change }\end{array}$ & $\begin{array}{l}\text { Revisions in } \\
\text { Expectations }\end{array}$ \\
\hline \multirow{3}{*}{ TB2y } & B-10 & 0.52 & -0.05 & $0.52 * *$ & 0.11 \\
\hline & B-5 & 0.51 & 0.11 & -0.33 & $0.73 * *$ \\
\hline & B-1 & 0.22 & $0.04 *$ & -0.10 & 0.24 \\
\hline \multirow{3}{*}{ TB3y } & B-10 & 0.48 & -0.07 & $0.60 * *$ & 0.00 \\
\hline & B-5 & 0.52 & 0.08 & -0.31 & $0.73 * *$ \\
\hline & B-1 & 0.38 & $0.05 * *$ & $-0.16 * *$ & 0.10 \\
\hline \multirow{3}{*}{ TB5y } & B-10 & 0.47 & -0.09 & $0.65 * *$ & -0.11 \\
\hline & B-5 & 0.50 & 0.07 & -0.35 & $0.59 * *$ \\
\hline & B-1 & 0.26 & 0.03 & $-0.13 *$ & 0.16 \\
\hline \multirow{3}{*}{ TB7y } & B-10 & 0.53 & -0.11 & $0.71 * *$ & -0.13 \\
\hline & B-5 & 0.56 & 0.05 & $-0.36^{*}$ & $0.59 * *$ \\
\hline & B-1 & 0.30 & 0.04 & -0.17 & 0.13 \\
\hline \multirow{3}{*}{ TB10y } & B-10 & 0.50 & -0.09 & $0.65 * *$ & -0.07 \\
\hline & B-5 & 0.52 & 0.05 & $-0.39 *$ & $0.46^{*}$ \\
\hline & B-1 & 0.31 & 0.04 & $-0.16^{* *}$ & 0.14 \\
\hline \multirow{3}{*}{ TB30y } & B-10 & 0.49 & -0.09 & $0.57 * *$ & -0.10 \\
\hline & B-5 & 0.29 & 0.01 & -0.30 & 0.21 \\
\hline & B-1 & 0.35 & 0.03 & $-0.15 * *$ & 0.03 \\
\hline
\end{tabular}

Post-1994, Before a Policy Easing

\begin{tabular}{|c|c|c|c|c|c|}
\hline & \multirow[b]{2}{*}{ Time Period } & & \multicolumn{3}{|c|}{ Explanatory Variables } \\
\hline & & $\mathrm{R}^{2}$ & Constant & $\begin{array}{l}\text { Anticipated } \\
\text { Change }\end{array}$ & $\begin{array}{l}\text { Revisions in } \\
\text { Expectations }\end{array}$ \\
\hline \multirow{3}{*}{ TB3 } & B-10 & 0.11 & -0.05 & 0.22 & -0.36 \\
\hline & B-5 & 0.41 & 0.02 & 0.23 & 0.21 \\
\hline & B-1 & 0.26 & 0.05 & $0.18^{*}$ & 0.01 \\
\hline \multirow{3}{*}{ TB6 } & B-10 & 0.08 & -0.05 & 0.16 & 0.02 \\
\hline & B-5 & 0.35 & -0.04 & 0.00 & 0.41 \\
\hline & B-1 & 0.31 & -0.01 & -0.01 & $0.35^{*}$ \\
\hline \multirow{3}{*}{ TB2y } & B-10 & 0.02 & -0.06 & -0.06 & 0.21 \\
\hline & B-5 & 0.21 & -0.03 & -0.14 & 0.41 \\
\hline & B-1 & 0.33 & -0.07 & -0.17 & $0.42 *$ \\
\hline \multirow{3}{*}{ TB3y } & B-10 & 0.05 & -0.06 & -0.07 & 0.27 \\
\hline & B-5 & 0.22 & 0.02 & 0.02 & 0.30 \\
\hline & B-1 & 0.31 & -0.07 & -0.20 & 0.38 \\
\hline \multirow{3}{*}{ TB5y } & B-10 & 0.01 & -0.06 & $\begin{array}{l}-0.07 \\
\end{array}$ & 0.13 \\
\hline & B-5 & 0.17 & 0.03 & 0.06 & 0.20 \\
\hline & B-1 & 0.25 & -0.08 & -0.21 & 0.33 \\
\hline \multirow{3}{*}{ TB7y } & B-10 & 0.01 & -0.02 & 0.05 & -0.08 \\
\hline & B-5 & 0.18 & 0.05 & 0.07 & 0.25 \\
\hline & B-1 & 0.22 & -0.08 & -0.19 & 0.28 \\
\hline \multirow{3}{*}{ TB10y } & B-10 & 0.01 & -0.05 & -0.08 & 0.02 \\
\hline & B-5 & 0.13 & 0.05 & 0.05 & 0.22 \\
\hline & B-1 & 0.24 & -0.07 & -0.18 & 0.31 \\
\hline \multirow{3}{*}{ TB30y } & B-10 & 0.02 & -0.04 & -0.09 & 0.07 \\
\hline & B-5 & 0.01 & 0.04 & 0.04 & 0.01 \\
\hline & B-1 & 0.16 & -0.03 & -0.07 & 0.23 \\
\hline
\end{tabular}




\section{Table 7. Term Structure After a Change ${ }^{21}$}

$T R_{t+i}-T R_{t}=\alpha+\beta_{1}(\text { anti } \Delta)_{t}+\beta_{2}(\text { unanti } \Delta)_{t}+\varepsilon_{t}$

\section{Pre-1994, After a Policy Easing}

\begin{tabular}{|c|c|c|c|c|c|}
\hline & \multirow[b]{2}{*}{ Time Period } & & \multicolumn{3}{|c|}{ Explanatory Variables } \\
\hline & & $\mathrm{R}^{2}$ & Constant & $\begin{array}{c}\text { Anticipated } \\
\text { Change }\end{array}$ & $\begin{array}{c}\text { Unanticipated } \\
\text { Change }\end{array}$ \\
\hline \multirow{4}{*}{ TB3 } & D & 0.52 & 0.05 & $0.38^{* *}$ & $0.75^{* *}$ \\
\hline & A-1 & 0.01 & 0.00 & 0.05 & 0.06 \\
\hline & A-5 & 0.04 & -0.07 & -0.20 & -0.12 \\
\hline & A-10 & 0.10 & -0.02 & -0.13 & 0.24 \\
\hline \multirow{4}{*}{ TB6 } & $\mathrm{D}$ & 0.60 & 0.06 & $0.44 * *$ & $0.78 * *$ \\
\hline & A-1 & 0.06 & -0.01 & 0.09 & -0.03 \\
\hline & A-5 & 0.12 & 0.10 & 0.36 & $0.37^{*}$ \\
\hline & A-10 & 0.09 & -0.04 & -0.24 & 0.12 \\
\hline \multirow{4}{*}{ TB2y } & $\mathrm{D}$ & 0.59 & $0.07^{*}$ & $0.43^{* * *}$ & $0.75^{* *}$ \\
\hline & A-1 & 0.12 & 0.03 & 0.24 & 0.05 \\
\hline & A-5 & 0.08 & 0.09 & 0.31 & 0.39 \\
\hline & A-10 & 0.08 & 0.01 & -0.05 & 0.25 \\
\hline \multirow{4}{*}{ TB3y } & $\mathrm{D}$ & 0.40 & 0.07 & $0.38^{*}$ & $0.64 * *$ \\
\hline & A-1 & 0.19 & 0.03 & $0.28 * *$ & 0.08 \\
\hline & A-5 & 0.13 & 0.12 & 0.49 & $0.51^{*}$ \\
\hline & A-10 & 0.04 & 0.00 & -0.06 & 0.16 \\
\hline \multirow{4}{*}{ TB5y } & $\mathrm{D}$ & 0.44 & $0.08^{*}$ & $0.37 * *$ & $0.64 * *$ \\
\hline & A-1 & 0.18 & 0.02 & $0.25^{*}$ & 0.05 \\
\hline & A-5 & 0.07 & 0.09 & 0.33 & 0.30 \\
\hline & A-10 & 0.01 & -0.01 & -0.02 & 0.06 \\
\hline \multirow{4}{*}{ TB7y } & $\mathrm{D}$ & 0.37 & 0.07 & $0.31 *$ & $0.51 * *$ \\
\hline & A-1 & 0.22 & 0.02 & $0.29 * *$ & 0.08 \\
\hline & A-5 & 0.10 & 0.08 & 0.35 & 0.33 \\
\hline & A-10 & 0.00 & 0.00 & -0.02 & 0.03 \\
\hline \multirow{4}{*}{ TB10y } & D & 0.27 & 0.06 & $0.30^{*}$ & $0.42 * *$ \\
\hline & A-1 & 0.19 & 0.02 & $0.24 * *$ & 0.08 \\
\hline & A-5 & 0.09 & 0.06 & 0.33 & 0.23 \\
\hline & A-10 & 0.00 & 0.00 & -0.03 & 0.02 \\
\hline \multirow{4}{*}{ TB30y } & $\mathrm{D}$ & 0.17 & 0.04 & 0.25 & $0.30 * *$ \\
\hline & A-1 & 0.13 & 0.01 & $0.19 *$ & 0.07 \\
\hline & A-5 & 0.03 & 0.02 & 0.19 & 0.12 \\
\hline & A-10 & 0.00 & 0.02 & 0.03 & 0.01 \\
\hline
\end{tabular}

\footnotetext{
${ }^{21}$ In order to present the estimation results in a compact form, we only report the coefficient estimates and indicate their significance as a superscript. $* *(*)$ indicates significant at the $95 \%(90 \%)$ confidence level.
} 
Table 7 (Continued)

Post-1994, After a Policy Tightening

\begin{tabular}{|c|c|c|c|c|c|}
\hline & \multirow[b]{2}{*}{ Time Period } & & \multicolumn{3}{|c|}{ Explanatory Variables } \\
\hline & & $\mathrm{R}^{2}$ & Constant & $\begin{array}{c}\text { Anticipated } \\
\text { Change }\end{array}$ & $\begin{array}{c}\text { Unanticipated } \\
\text { Change }\end{array}$ \\
\hline \multirow{4}{*}{ TB3 } & $\mathrm{D}$ & 0.72 & 0.01 & 0.00 & $0.74 * *$ \\
\hline & A-1 & 0.18 & -0.03 & -0.09 & 0.24 \\
\hline & A-5 & 0.63 & $0.12 * *$ & $-0.41 * *$ & 0.07 \\
\hline & A-10 & 0.03 & -0.04 & 0.09 & 0.26 \\
\hline \multirow{4}{*}{ TB6 } & $\mathrm{D}$ & 0.30 & 0.00 & -0.05 & $0.52 *$ \\
\hline & A-1 & 0.18 & -0.01 & -0.10 & 0.19 \\
\hline & A-5 & 0.18 & 0.09 & -0.33 & 0.27 \\
\hline & A-10 & 0.06 & 0.03 & -0.04 & 0.36 \\
\hline \multirow{4}{*}{ TB2y } & $\mathrm{D}$ & 0.18 & 0.07 & -0.26 & 0.42 \\
\hline & A-1 & 0.06 & -0.04 & 0.11 & -0.06 \\
\hline & A-5 & 0.11 & 0.11 & -0.18 & -0.32 \\
\hline & A-10 & 0.17 & 0.06 & -0.27 & 0.81 \\
\hline \multirow{4}{*}{ TB3y } & $\mathrm{D}$ & 0.19 & 0.06 & -0.27 & 0.49 \\
\hline & A-1 & 0.02 & -0.02 & 0.06 & -0.01 \\
\hline & A-5 & 0.20 & 0.12 & -0.13 & -0.65 \\
\hline & A-10 & 0.20 & 0.09 & -0.39 & 0.86 \\
\hline \multirow{4}{*}{ TB5y } & $\mathrm{D}$ & 0.18 & 0.06 & -0.31 & 0.42 \\
\hline & A-1 & 0.03 & -0.02 & 0.05 & 0.12 \\
\hline & A-5 & 0.20 & 0.13 & -0.12 & -0.86 \\
\hline & A-10 & 0.26 & 0.10 & -0.49 & 0.92 \\
\hline \multirow{4}{*}{ TB7y } & $\mathrm{D}$ & 0.17 & 0.07 & -0.35 & 0.34 \\
\hline & A-1 & 0.13 & -0.05 & 0.15 & 0.08 \\
\hline & A-5 & 0.28 & 0.16 & -0.19 & $-1.11 *$ \\
\hline & A-10 & 0.34 & 0.11 & $-0.54 *$ & $1.11^{*}$ \\
\hline \multirow{4}{*}{ TB10y } & $\mathrm{D}$ & 0.19 & 0.06 & -0.33 & 0.32 \\
\hline & A-1 & 0.07 & -0.04 & 0.10 & 0.10 \\
\hline & A-5 & 0.25 & 0.13 & -0.13 & $-1.01 *$ \\
\hline & A-10 & 0.40 & 0.11 & $-0.58^{*}$ & $1.13^{*}$ \\
\hline \multirow{4}{*}{ TB30y } & $\mathrm{D}$ & 0.20 & 0.04 & -0.27 & 0.22 \\
\hline & A-1 & 0.10 & -0.03 & 0.07 & 0.20 \\
\hline & A-5 & 0.17 & 0.14 & -0.21 & -0.63 \\
\hline & A-10 & 0.48 & 0.12 & $-0.54 * *$ & $0.92 * *$ \\
\hline
\end{tabular}


Table 7 (Continued)

Post-1994, After a Policy Easing

\begin{tabular}{|c|c|c|c|c|c|}
\hline & \multirow[b]{2}{*}{ Time Period } & & \multicolumn{3}{|c|}{ Explanatory Variables } \\
\hline & & $\mathrm{R}^{2}$ & Constant & $\begin{array}{c}\text { Anticipated } \\
\text { Change }\end{array}$ & $\begin{array}{c}\text { Unanticipated } \\
\text { Change }\end{array}$ \\
\hline \multirow{4}{*}{ TB3 } & $\mathrm{D}$ & 0.29 & 0.03 & 0.19 & $0.42 *$ \\
\hline & A-1 & 0.23 & -0.08 & -0.11 & 0.39 \\
\hline & $A-5$ & 0.00 & 0.01 & 0.01 & -0.01 \\
\hline & A-10 & 0.34 & 0.14 & 0.53 & 0.05 \\
\hline \multirow{4}{*}{ TB6 } & $\mathrm{D}$ & 0.33 & 0.03 & 0.24 & $0.41 *$ \\
\hline & A-1 & 0.24 & -0.07 & -0.15 & 0.25 \\
\hline & A-5 & 0.02 & 0.06 & 0.15 & 0.10 \\
\hline & A-10 & 0.15 & 0.04 & 0.19 & -0.04 \\
\hline \multirow{4}{*}{ TB2y } & $\mathrm{D}$ & 0.01 & -0.02 & 0.08 & 0.05 \\
\hline & A-1 & 0.13 & -0.02 & -0.03 & 0.22 \\
\hline & A-5 & 0.02 & -0.01 & -0.12 & 0.02 \\
\hline & A-10 & 0.03 & -0.09 & -0.18 & -0.23 \\
\hline \multirow{4}{*}{ TB3y } & $\mathrm{D}$ & 0.01 & -0.03 & 0.03 & -0.02 \\
\hline & A-1 & 0.06 & -0.03 & -0.03 & 0.12 \\
\hline & A-5 & 0.11 & -0.06 & -0.27 & -0.06 \\
\hline & A-10 & 0.01 & -0.03 & -0.09 & -0.11 \\
\hline \multirow{4}{*}{ TB5y } & $\mathrm{D}$ & 0.03 & -0.05 & -0.07 & -0.13 \\
\hline & A-1 & 0.02 & -0.05 & -0.08 & -0.01 \\
\hline & A-5 & 0.07 & -0.02 & -0.22 & -0.06 \\
\hline & A-10 & 0.01 & -0.03 & -0.14 & -0.04 \\
\hline \multirow{4}{*}{ TB7y } & $\mathrm{D}$ & 0.09 & -0.06 & -0.09 & -0.21 \\
\hline & A-1 & 0.00 & -0.04 & -0.05 & -0.02 \\
\hline & A-5 & 0.09 & -0.02 & -0.20 & -0.02 \\
\hline & A-10 & 0.02 & -0.01 & -0.12 & 0.05 \\
\hline \multirow{4}{*}{ TB10y } & $\mathrm{D}$ & 0.16 & -0.07 & -0.12 & -0.27 \\
\hline & A-1 & 0.00 & -0.03 & -0.03 & -0.02 \\
\hline & A-5 & 0.00 & 0.00 & -0.06 & -0.07 \\
\hline & A-10 & 0.02 & 0.03 & -0.08 & 0.07 \\
\hline \multirow{4}{*}{ TB30y } & $\mathrm{D}$ & 0.41 & -0.06 & -0.10 & $-0.29 * *$ \\
\hline & A-1 & 0.05 & -0.02 & -0.01 & -0.09 \\
\hline & A-5 & 0.02 & -0.03 & -0.13 & -0.13 \\
\hline & A-10 & 0.11 & 0.08 & 0.06 & 0.32 \\
\hline
\end{tabular}




\section{References}

Akhtar, M. A. (1997), Understanding Open Market Operations, Public Information Department, Federal Reserve Bank of New York.

Anderson, R. G. and Raasche, R. H. (2000), "Retail Sweep Programs and Bank Reserves, 1994-1999," Federal Reserve Bank of St. Louis, working paper 2000023A.

Bartolini, L., Bertola, G. and Prati, A. (2000), "Day-to-Day Monetary Policy and the Volatility of the Federal Funds Interest Rate," Federal Reserve Bank of New York, Staff Report no. 110.

Cook, T. and Hahn T. (1989), "The Effect of Changes in the Federal Funds Rate on Market Interest Rates in the 1970s," Journal of Monetary Economics, 24, 33-51.

Clouse, J. A. (1994), "Recent Developments in Discount Window Policy," Federal Reserve Bulletin, November 1994

Clouse, J. A. and Dow, J. P. (2000), “A Computational Model of Banks' Optimal Reserve Management Policy," Federal Reserve Board, manuscript.

Cohen, G. D. (1997), “Open Market Operations during 1996," Federal Reserve Bulletin, July 1997.

Demiralp S., and Jordá O. (2000), "The Announcement Effect: Evidence from Open Market Desk Data," Economic Policy Review, Federal Reserve Bank of New York, forthcoming.

Demiralp S., and Jordá O. (2001), "The Pavlovian Response of Term Rates to Fed Announcements," Federal Reserve Board Working Papers, Finance and Economics Discussion series, 2001-10.

Edwards C. L. (1997), “Open Market Operations in 1990s,” Federal Reserve Bulletin, November 1997.

Feinman J. (1993), "Estimating the Open Market Desk's Daily Reaction Function," Journal of Money, Credit, and Banking, Vol. 25, No 2.

Ferguson R. W. (2001), “Transparency in Central Banking: Rationale and Recent Developments" Remarks at the National Economists Club and Society of Government Economists, Washington D.C. April 19, 2001

Furfine, C. H. (2000), "Interbank Payments and the Daily Federal Funds Rate," Journal of Monetary Economics, 46, 535-553.

Guthrie, G., and Wright, J. (2000), "Open Mouth Operations," Journal of Monetary Economics, 46, Issue 2, 489-516.

Hamilton, J. D. (1996), "The Daily Market for Federal Funds," Journal of Political Economy, 104, 26-56. 
Hamilton J. D., and Jordá O. (2000), "A Model for the Federal Funds Rate Target," NBER working paper 7847.

Hilton, S. (1999), "Highlights of Domestic Open Market Operations during 1998," Federal Reserve Bulletin, April 1999.

Kohn, D. (1991), "Alternative Operating Procedures," Cover letter to the Federal Open Market Committee, August 14, 1991.

Kuttner, K. N. (2001), "Monetary Policy Surprises and Interest Rates: Evidence from the Fed Funds Futures Market," Journal of Monetary Economics, 47, pp. 447-676

Lange J., Sack B., and Whitesell W. (2001), "Anticipations of Monetary Policy in Financial Markets," Federal Reserve Board Working Papers, Finance and Economics Discussion series, 2001-24.

Mayer, M. (2001), The Fed: The Inside Story of How the World's Most Powerful Financial Institution Drives the Market, Free Press.

Meyer L. H. (2001a), “Does Money Matter?” Homer Jones Memorial Lecture, Washington University, St. Louis, Missouri, March 28,2001.

Meyer L. H. (2001b), "Comparative Central Banking and the Politics of Monetary Policy," Remarks at the National Association for Business Economics Seminar on Monetary Policy and the Markets, Washington, D.C. May 21, 2001.

Meulendyke, A M. (1998), U.S Monetary Policy and Financial Markets, Federal Reserve Bank of New York.

Orphanides, Athanasios (2001), Comments on: "Expectations, Open Market Operations, and Changes in the Federal Funds Rate," by John B. Taylor. Federal Reserve Bank of St. Louis, Review, forthcoming.

Poole W., Rasche R. H., Thornton D.L. (2001), "Market Anticipations of Monetary Policy Actions," Federal Reserve Bank of St. Louis, Working Paper

Taylor, J B. (2001), "Expectations, Open Market Operations, and Changes in the Federal Funds Rate," Federal Reserve Bank of St. Louis, Review, forthcoming.

Thornton, D. L. (2001), “ The Market Reaction to Changes in the Fed's Fund Rate Target: Has the Fed Used Open Mouth Operations?" Federal Reserve Bank of St. Louis, Review, forthcoming. 